\title{
MINDFUL AND MINDLESS ANTHROPOMORPHISM: HOW TO FACILITATE CONSUMER COMPREHENSION TOWARDS NEW PRODUCTS
}

\begin{abstract}
Individual's perception of anthropomorphic platforms in promotion of really new products or novel innovations has not been examined fully. There are contradictions in the academic literature on how various presentations of social cues are perceived by audience mindlessly or mindfully. Perceived mindful and mindless anthropomorphism are explored in this study in order to understand its effect on individuals' attitude, purchase intention and comprehension of new products. A single factor betweensubject design using two innovative products and websites with four levels of social cues (voice, language, interactivity and social role) was used. Five hundred participants took part in the main experiment. Participants were randomly assigned to each experimental group. The analysis indicated that a human-like avatar is preferred by individuals over static avatar and perceived higher mindlessly. Interactive content didn't improve individuals' perceived mindless anthropomorphism. There was no significant increase in individuals' mindful anthropomorphism in any condition. The study indicated perceived mindless anthropomorphism results into better comprehension, attitude and purchase intention towards really new products.
\end{abstract}

Keywords: Perceived anthropomorphism, Innovation, Avatars, Social Cues

\section{Introduction}

Due to consumers' increased attention and preference towards information presented via a Computer Mediated Environment (CME), online advertising and product presentation have become of interest to academics (e.g. Robinson et al., 2007; Van Noort, 2012). CMEs, particularly the internet, are used as promotional channels for new product awareness (Bickart and Schindler, 2001) and have been studied extensively (e.g. Yi et al. 2015; Mengxiang et al. 2016). The use of the internet rather than more traditional promotional tools, has resulted in an increase in the innovation adoption rate (Prince and Simon, 2009). CMEs are therefore suitable platforms for promoting new products and services and can be used to increase consumer awareness and encourage innovation adoption. Consequently, academics are exploring elements such as interactivity (Chung and Zhao, 2004) and anthropomorphic attributes that differentiate online product promotion from traditional media promotion. Anthropomorphic attributes is shown to influence consumers behaviour (e.g. Holzwarth et al., 2006; Franceschi et al., 2009; Guttentag, 2010; Keeling et al. 2010; Bennett and Thompson 2016) and is used in CMEs as a way to improve human-computer interactions (Gong, 2008, Bennett and Thompson 2016). Anthropomorphism can include interactivity, which is a central theme in the marketing communication literature (Kim and McMillan, 2008).

Including anthropomorphic attributes in an online setting for product promotion is particularly important for presenting information about Really New Products (RNPs) that are a strategic priority for many businesses (Dereli 2015; Feiereisen et al., 2008). Research suggests that if individuals perceive anthropomorphism as an attribute of a website, then this will have a positive effect on their level of trust, will reduce uncertainty, and will positively affect behaviour (Hoeffler, 2003; Castano and Giner-Sorolla, 2006). This is particular important with RNPs as innovation adoption involves a higher level of uncertainty than existing product adoption (Slade et al. 2015; Alexander et al., 2008). A higher level of perceived anthropomorphism can also lead to increased learning (e.g. Bandura's 1977). Avatars that are perceived as anthropomorphic create an expectation of sociability, and stimulate judgments reserved for social entities like credibility and homophily (Bente et al., 2008). Yet a human-like avatar can also be perceived negatively by individuals (e.g. Gammoh et al. 2018; Groom et al., 2009; Keeling et al., 2010). Expectations of realism and/or sociability that are not met may lead to negative consumer outcomes (Reeves and Nass, 1996; Nowak and Biocca, 2003; Nowak, 2004). So, although participants tend to prefer a more realistic, human-like avatar in comparison to avatars with a more cartoon-like or abstract appearance, a more human-like avatar presents a higher risk of disappointment due to participants' higher expectations (Keeling, 2010). The Uncanny Valley Theory (Mori 1970), which posits that highly realistic agents receive more negative evaluations than agents that demonstrate only moderate realism (Mori, 1970; Groom et al., 2009), may explain the apparent contradictory impact of anthropomorphism. Consequently, 
exploring the different types of anthropomorphic attributes to understand their influence on consumer perception within the novel innovation or RNP context, and in turn their influence on consumer comprehension and behaviour, is needed. Hence the question is what are the effect of recruiting various anthropomorphic attributes on RNP comprehension and consumers' behavior towards them?

RNPs unique characteristics may have an impact on how social cues, such as those provided by anthropomorphism and interactivity, impact individuals' behaviour. RNPs are products that require the consumer to understand new concepts related to the benefits derived from the product; this may be related to explicitly recognising an unidentified need, or to a novel way of satisfying a known need (or both). Examples of RNPs are the 'ipod' at the time of introduction to the marketplace or the 'Electrolux Bio Robot Refrigerator ${ }^{1}$ '. As no/little information is available about RNPs, customers learning about RNPs need to process the information at the time of product evaluation and construct preferences at the time of measurement (Hoeffler 2003). This learning process differs from learning about most products where some pre-existing knowledge is accessible to the consumer (Hoeffler 2003, Feiereisen 2009). Hence, it is important to understand the impact of social cues on consumer behaviour and leaning within RNP context as there is no literature within the context of RNPs and anthropomorphism. To address this gap, the study examines individuals' behavior towards RNPs presented using various anthropomorphic attributes to uncover how different social cues impact customers' behavior and comprehension. .

\section{Literature Review and Theoretical Background \\ 2.1. Really New Products}

Really New Products (RNPs) are novel innovative products, allowing consumers both to experience something they have not experienced before, and to perform tasks they are not able to perform using existing products. An example which is used in this paper is "Washing Machine-in Wardrobe" "that washes cloths while hanging in the wardrobe (more information in appendix 1). Consumers may need to change their behaviour in order to achieve the full potential of RNPs (Alexander et al., 2008; Hoeffler and Herzenstein 2015). RNPs are considered a higher-risk, higher-reward product category than other product types (Hoeffler, 2003). Consumers consequently face more uncertainty dealing with RNPs than familiar products, and individuals need to put more cognitive effort into understanding RNPs to reduce this uncertainty (e.g. Gregan-Paxton et al., 2002; Feiereisen et al., 2008; Hoeffler and Herzenstein 2015). This means that effort is required by consumers to understand RNPs, but full understanding of RNPs can only occur when the product is used (Hoeffler, 2003). Consequently, RNP information needs to be presented in a way that facilitates consumers learning and reduces uncertainty.

When presenting information to consumers, the employment of anthropomorphic attributes increases information credibility (Holzwarth et al., 2006; Liew et al. 2017) leading to lower perceived risk and reducing consumer uncertainty which is useful when learning about RNPs (Hoeffler, 2003; Castano and Giner-Sorolla, 2006). Learning theories within different frameworks support the employment of anthropomorphic attributes as a means of improving consumer comprehension (e.g. Bandura's (1997) Social Learning Theory). Humancomputer interaction research also supports inserting anthropomorphic attributes in websites to facilitate the process of learning (e.g. Tu, 2000; Keeling et al., 2010). The comprehension of a RNP, according to Persuasion Theory, is a precondition to the formation of consumer attitudes, intentions and behaviours (e.g. Ratneshwar and Chaiken, 1991); adding anthropomorphic attributes can therefore improve consumer attitude and intention towards RNPs. As such, employing anthropomorphic attributes on a website is likely to facilitate consumer learning about RNPs, as well as decrease consumer uncertainty, thus resulting in more positive consumer behaviour.

\subsection{Anthropomorphism}

Social Cognition Theory, derived from Bandura's (1977) Social Learning Theory, explains the classification of entities as humans, animals or objects and posits that recognition of anthropomorphic characteristics is a basic cognitive function (Kunda, 1999). Anthropomorphism, as "an interpretation of what is not human or personal in terms of human or personal characteristics" (Merriam-Webster Collegiate Dictionary, 2004, p.53), as such classifies an object/nonhuman entity based on human characteristics. Anthropomorphism is used to describe any

\footnotetext{
'https://www.yankodesign.com/2010/06/21/bio-robot-refrigerator/?utm_source=thisiswhyimbroke.com\&utm_medium=referral

${ }^{2}$ https://ifworlddesignguide.com/entry/78391-washing-machine-in-wardrobe
} 
kind of "dispositional inference about a nonhuman agent" (Waytz et al., 2014, p.220). Extending this to IT, 'social cues' refer to various types of anthropomorphic attributes (Wang et al., 2007), and in CMEs individuals perceive anthropomorphism when dealing with different types of social cues. Social Response Theory holds that "the more computers present characteristics that are associated with humans, the more likely they [i.e., computers] are to elicit social behaviour" (Nass and Moon, 2000, p.97). Consequently, the more computers possess social cues, the more people respond to those computers with their pre-existing social scripts (Sundar and Nass, 2000; Posard and Rinderknecht 2015). As a result, people apply social rules to computers and then respond to their interactions with computers according to those social rules (Nass and Steuer, 1993).

Four social cues are particularly relevant to eliciting social responses from consumers, these are the human voice, language, interactivity and social role (Nass and Steuer, 1993). Human voice, as a social cue, encourages individuals to apply human-human interaction rules to their relationship with a CME (Reeves and Nass, 1996). Nass and Steuer showed, for example, that people react to different voices on the same computer as if they are different social actors. Language has also been employed in almost all computer-mediated interfaces as an important tool for communication, mainly in the form of text rather than as spoken language (Wakefield et al., 2011). The use of strong (commands and assertions) or weak (suggestions and questions) language on a screen, creates the perception of different personalities (Nass et al., 1995). The third social cue, Interactivity, consists of two-way communication, active control and immediate feedback (Liu and Shrum, 2002). Interactivity can increase perceived anthropomorphism and consequently positively impact consumer behaviour (Liu and Shrum, 2002; Wakefield et al., 2011). Finally social role cues are concerned with how individuals define entities, including themselves, as human according to the role that other entities play (i.e. Nass et al. 2005; Wallace, 1983).

Social cues, often through anthropomorphic attributes, are the "technological efforts of imbuing computers with human characteristics and capabilities" (Gong, 2008, p.1495). Social cues can result into consumer pleasure (Das and Varshneya 2017), stimulate social responses in consumers/users such as considering a nonhuman object as friendly, committed, polite, connected or intelligent (Nass and Steuer, 1993; Posard and Rinderknecht 2015; Kang and Kim 2020) and create connective affordance (Tang and Zhang 2018). In line with these social cues, anthropomorphic attributes are operationalized in various forms including anthropomorphized interface representations, like faces (Sproull et al., 1996; Gong and Nass, 2007) and voices (Gong and Lai, 2003; Nass and Brave, 2005), and linguistic cues such as giving agents human names (Xu and Lombard 2017) as well as including interactive elements online (Isbister and Nass, 2000) or incorporating social cues in design cues (Araujo 2018). Nass et al. (1997) for instance demonstrated that computers with voice output provoked gender stereotypes. Moon (2000) claimed that when consumers are interacting with computers and have provided some information about themselves, they become involved in intimate self-disclosure (Moon, 2000). However, researchers do not seem to have directly explored the link between social cues and anthropomorphism when considering RNPs.

To summarize, various social cues have proved to influence learning and behaviour. As language is generally required to communicate the benefits of RNPs to consumers in the online environment, the social cue of language does not provide a differentiating factor when considering anthropomorphism for the perspective of social cues. Nevertheless, as inserting various social cues can facilitate consumer comprehension towards RNPs, understanding how consumers perceive online social cues is critical to maximising comprehension of RNPs. Interactivity, as a social cue, can be applied to both online content, and interactions with an online agent. While the former does not require an avatar, in the CME interacting with an online agent might occur through an avatar whereas content interactivity can simply include an interactive tool.

\subsection{Content Interactivity}

Interactivity, as defined by Steuer (1992, p.84), is "the extent to which users can participate in modifying the form and content of a mediated environment in real time". A later definition described interactivity as a multidimensional concept that includes active control, two-way communication, and synchronicity (Lui and Shrum, 2002). Synchronicity provides immediate feedback, the simultaneousness of users input into a communication and the response they receive. Two-way communication and immediate feedback are the main characteristics in interpersonal communication (Wang et al., 2007). In a user-computer interaction, individuals perceive more interactivity when communication more closely resembles interpersonal communication (Ha and James, 1998; Walther et al. 2015) therefore if synchronicity and two-way communications are implemented 
within a CME, individuals should perceive the communication as interpersonal and interactive. That is, as a social cue.

Due to the nature of web browsing, all websites have some degree of interactivity. However, by considering synchronicity and two-way communication (Wang et al., 2007), websites can become more interpersonal. Content interactivity can provide a more interpersonal platform for consumers, being anything from an interactive video to an interactive 3D design. Content choices can improve immediate feedback to the person and produce a two-way communication within the CME. Furthermore, content interactivity can resemble the human-like interactivity of a CME and create website socialness, which then leads to improved perceived anthropomorphism (e.g. Liu and Shrum, 2002; Wakefield et al., 2011).

\subsection{Online agents - Avatars}

An example of anthropomorphism employed in an online setting is the online agent (avatar). In CMEs, an avatar is a representation of an entity; for example, a "pictorial representation of a human in a chat environment" (Bahorsky et al., 1998, p.8) or "general graphic representations that are personified by means of computer technology" (Holzwarth et al., 2006, p.20). Avatars are also defined as "virtual characters that can be used as company representatives and can serve as identification figures, personal shopping assistants, web site guides or as conversation partners ... avatars can anthropomorphize the interaction and make the shopping experience more interpersonal" (Holzwarth et al., 2006, p.19). Avatars have also been referred to in different terms, such as embodied conversational agents (ECAs) (Cassell et al., 2000), virtual agents (Abbattista et al., 2002), synthetic personae (McBreen and Jack, 2001), interactive characters (Isbister and Nass, 2000), animated pedagogical agents (Lester et al., 1997), artificial shopping agents (Redmond, 2002) and animated interface agents (Dehn and van Mulken, 2000).

Research on avatars has generally examined their human morphology/appearance, not their behaviour (e.g. Fox et al. 2015; Nowak and Rauh, 2005). Avatar morphology has two main dimensions: androgyny, a rating of the avatar's (lack of) masculinity or femininity and avatar humanness, or the extent to which the avatar looks human (Nowak and Rauh, 2005; Nowak et al., 2008). Androgyny is sometimes operationalized as the position on which the avatar's image falls on the masculinity-femininity continuum (Nowak et al., 2008). Human-like and visibly gendered avatars are more attractive and credible than androgynous avatars (Jin, 2009), and feminine avatars are more attractive than masculine avatars (Nowak and Rauh, 2005). An avatar's morphology can vary in the extent to which it realistically resembles human appearances or characteristics. For example, avatar appearance and attractiveness is positively related to avatar friendliness ( $\mathrm{Li}$ et al. 2018). Also avatars can be designed to be, and used as, very realistic and human-like vs. a simple picture or cartoon character (Kim and Sundar 2012).

Avatars also vary in the degree to which they are interactive. This interactivity is not solely dependent on a human-like appearance, although the division between human-like (or interactive) and static (or image) avatars is common. Whether human-like avatars or static avatars are perceived as more anthropomorphic, however, is not straightforward. Avatars designed to match head and eye movement to the conversational flow are perceived as more trustworthy and friendly (Donath, 2007), human-like spokes-avatars are perceived as more attractive and credible than static avatars (e.g. Nowak and Rauh, 2005; Jin, 2009) and virtual humans showing cooperative facial displays such as joy are more favoured (de Melo et al. 2014). However, there is also evidence that a more human-like avatar is evaluated more negatively (e.g. Groom et al., 2009; Keeling et al., 2010).

Static avatars are anthropomorphic images that represent human characteristics. They are known to be engaging, interesting and attractive (Nowak, 2004). Studies have examined the use of static avatars and how they are perceived as anthropomorphic (e.g. Kim and Sundar 2012). Human-like avatars are interactive animated characters that communicate using voice and movement. They have been employed to improve consumer experience online. They are perceived as attractive (Nowak and Rauh, 2005; Jin, 2009), credible (Nowak and Rauh, 2005), and are easily understood (Burgoon et al. 2009). While interacting with a human-like avatar, participants feel more positive about the information presented to them in comparison to a no-avatar condition. Introducing a human-like avatar will result in improved perceived anthropomorphism as opposed to a no-avatar condition (i.e. Arauji 2018). Research has shown that the use of human-like avatars increases the level of social presence in an online setting (Hale and Stiff, 1990; Etemad-Sajadi R. 2016) and creates an automatic social response (Lee and Nass, 2003). 
While introducing an anthropomorphic element to a CME is usually positive, how 'human' the optimal avatar should be, has not been determined. So while human-like avatars can result in better comprehension and increased feelings of social presence (e.g. Araujo 2018; Burgoon et al. 2009; Lee and Nass 2003), this is not always the case (e.g. Mori, 1970; Nowak and Biocca, 2003). As Mori (1970) observed in robots, non-realistic robots can be perceived as more likeable, whereas very life-like robots may be perceived as disturbing. Highly realistic agents can also receive more negative evaluations than agents that demonstrate only moderate realism (Mori, 1970; Groom et al., 2009; Gammoh et al. 2018). So making avatars as realistic as possible might not optimise anthropomorphism (e.g. Kim and Sundar, 2012). This may be because avatars that are perceived as anthropomorphic create an expectation of sociability, and stimulate judgments reserved for social entities like credibility and homophily (e.g. Bente et al., 2008). When the users' expectations are not met, negative attributions follow (Reeves and Nass, 1996; Nowak and Biocca, 2003; Nowak, 2004). While participants tend to express a preference for a more realistic, human-like avatar vis-à-vis a cartoonish avatar, there is also a higher risk of disappointment due to a higher expectation of participants (Keeling, 2010).

When looking at avatars in terms of the social cues they provide, human-like avatars have more potential to provide social cues (i.e., present anthropomorphic qualities), than static avatars, though static avatars still provide social cues over those found in CMEs without avatars. As anthropomorphism is linked to social cues, it can be suggested that a higher level of social cues result in a higher level of perceived anthropomorphism. However, research indicates that individuals perceive anthropomorphism both mindlessly and mindfully.

\subsection{Mindful and Mindless Anthropomorphism}

It is important to understand how individuals perceive anthropomorphism within CMEs, including what their point of reference is towards the interaction in CMEs is; content, avatar or both. Anthropomorphism can be perceived consciously (mindfully) or unconsciously (mindlessly) (e.g. Kim and Sundar, 2012). Mindful anthropomorphism is when participants consciously rate a CME as anthropomorphic. Nass and Moon (2000, p.93) justify the mindful nature of anthropomorphism by referring to the definition of anthropomorphism as " $a$ thoughtful, sincere belief that the object has human characteristics". Much of the research examining mindful anthropomorphism is within the Human Robot Interaction (HRI) literature (e.g. Powers and Kiesler, 2006; Bartneck et al., 2009). However, these categorizations have also been employed within the CME literature while studying the employment of social cues such as avatars (e.g. Nowak and Rauh, 2005).

Mindless anthropomorphism is explained via a heuristic systematic model (Chaiken, 1987) and the MAIN model (Sundar, 2008). These models describe how heuristic cues trigger a consumer's unconscious responses towards anthropomorphic attributes. Kim and Sundar (2012) explains how richer modality cues elicit a "realism heuristic" (Kim and Sundar, 2012, p.242), which imitates face-to-face communication. Richer modality cues further provoke agency affordance, which refers to any evidence of the existence of an intelligent entity within the context of interaction, leading to a "social presence heuristic" (Kim and Sundar, 2012, p.242). Studies have manipulated anthropomorphism by employing an avatar and directly asking consumers if the character is human-like, machine-like, natural and so on (e.g. Groom et al., 2009; Keeling et al., 2010). Kim and Sundar (2012) argued that this approach denies the mindless anthropomorphism individuals perceived within CMEs. As such, they further developed perceived mindful anthropomorphism and mindless anthropomorphism scales to measure individuals' reaction towards various social cues.

Mindless anthropomorphism can be linked to another type of perceived anthropomorphism discussed within the CME context - perceived website anthropomorphism, or website socialness. Perceived website anthropomorphism is strongly linked to Social Response Theory (Moon, 2000), and is used in studies to "describe the phenomenon of users treating technology or technology interface such as websites as social actors" (Wakefield et al., 2011, p.119). Perceived website anthropomorphism refers to "the extent to which consumers detect socialness on a website" such as politeness and friendliness (Wakefield et al., 2011, p.119). Wakefield (2011) further links back to literature suggesting that perceived anthropomorphism is a mindless act (e.g. Langer, 1989; Nass and Moon, 2000); an individual's automatic reaction towards human-computer interaction is based on the heuristic aspect of the information provided (e.g. Reeves and Nass, 1996). Any interactive content enhancing visual modality results in an improved mindless anthropomorphism similar to virtual agents, as rich media can transit social cues (Wang et al., 2007). Nass and Carney (1999) realized that increased interactivity escalates the possibility of users' automatic social response towards the technology. Kim 
and Sundar (2012) further echoed that mindless anthropomorphism increases when individuals deal with a high interactivity condition.

As well as contributing to interactive content, an avatar will enrich the audio and visual modalities in a CME by making the experience as close as possible to one-to-one communication. Avatars have been considered as a "way of improving interactivity and giving a more human touch" to the CME (Mimoun et al., 2012, p.605). Employing avatars will also lead to a better social presence heuristic, leading to an increased unconscious response towards the social cues presented. Hence it is proposed that:

H1: A website presenting RNPs with an avatar (static or human-like) will result in higher mindless anthropomorphism than a website with no avatar.

While perceived anthropomorphism has a positive impact on perceptions of RNPs, research presents contradictory evidence concerning how best to induce perceived anthropomorphism. Some studies revealed how inserting a static avatar online has improved consumers' perceived level of mindless anthropomorphism (i.e. Kim and Sundar, 2012). Kim and Sundar (2012, p.249) further explained "anthropomorphic cues do not have to be fancy in order to elicit human-like attribution". They explained that mindless anthropomorphism was induced using a simple static cartoon-like avatar online. Conversely, a more human-like interactive avatar is attractive and the information provided by them is perceived as credible (e.g. Nowak and Rauh, 2005; Jin, 2009: Mull et al. 2015). Studies support the employment of an interactive avatar to improve an individual's perceived anthropomorphism (Lee and Nass, 2003; Jin, 2009; Kang and Gratch, 2014). Furthermore, employing a close to real virtual agent will result in realism, as well as social presence, heuristics. These contradictions support the necessity of exploring the nature of individual's perceived anthropomorphism when interacting with CMEs including various social cues.

As explained above, content interactivity as another element resulting into $\mathrm{n}$ enhanced perceived anthropomorphism. Content interactivity can resemble the human-like interactivity of a CME which then result into an improved perceived anthropomorphism (e.g. Liu and Shrum, 2002; Wakefield et al., 2011). 3D objects create interactive content and two way communication. Therefore, it may be that the use of a 3D design would allow consumers to easily interact with a RNP unconsciously triggering social cues and facilitating learning. A 3D design would also enable the consumer to directly relate to product information. In contrast, an avatar would act by indirectly presenting product information that is not easily observable. The conscious human-like representation would not unconsciously trigger social cues. It is therefore predicted that:

$\mathbf{H}_{2}$ : A website presenting RNPs with interactive content will result in higher mindless anthropomorphism, than a website with an avatar (static or human-like).

The use of mindful anthropomorphic scales was challenged by Kim and Sundar (2012). They posited that if anthropomorphism occurs mindlessly, participants who are exposed to a human-like avatar should mindlessly, not mindfully, perceive it as more anthropomorphic. The result of Kim and Sundar's (2012) experiment showed that participants reported a lesser degree of mindful anthropomorphism (human-likeness) when dealing with a human-like avatar. They concluded that individuals intentionally deny treating the website as human-like when they were dealing with a human-like avatar. Further experiments revealed that participants reported a low mindful anthropomorphism when exposed to a human-like avatar or high interactivity, but a high mindless perceived anthropomorphism compared to the conditions of no-avatar or low interactivity (Kim and Sundar, 2012). As such, it does appear that the more social cues were forced, the less likely individuals mindfully perceived a website as anthropomorphic. The human-like avatar, as opposed to a static avatar, may be perceived as a forced social cue, and according to the Uncanny Valley Theory (Mori, 1970), can result in a more negative evaluation. Interactive content, as the least obvious presentation of social cues online, is likely to be perceived as more mindfully anthropomorphic. Therefore:

$\mathbf{H}_{3}$ : When individuals are exposed to less social cues through websites presenting RNPs, they mindfully perceive the website as anthropomorphic.

\subsection{Anthropomorphism and Comprehension}

Various social cues, as identified by Nass and Steuer (1993), have been studied to understand their impact on individuals' comprehension. Interactivity is supported by many learning theories and research for improving consumer's comprehension (e.g. Brandt, 1997; Zhang et al., 2006). Mayer (1997a; 1997b; Moreno \& Mayer, 2007), who has looked at learning in the multimedia environment explained how infusing interactivity in a learning environment results into an improved learning transfer and performance. Domagk, Schwartz and Plass 
(2010) define interactivity as "reciprocal activity between a learner and a multimedia learning system, in which the [re] action of the learner is dependent upon the [re] action of the system and vice versa" (Domagk et al., 2010, p.1025). In addition, as people react to computers as social actors (e.g. Reeves and Nass, 1996), users interactions with computers can be seen as social interactions. Bandura's (1977) Social Learning Theory explains how learning occurs as a result of people's social interactions in their environment (Walther, 1992). Social presence, for example, impacts positively on comprehension. Behaviour, personal factors and an ideal social environment can promote learning, providing an appropriate degree of social presence (Tu, 2000). As more $\mathrm{c}$ is required to comprehend RNPs, inserting social cues into CMEs promoting RNPs is beneficial for individuals in order to learn and comprehend these products. Consequently, interactive content could result in higher mindless anthropomorphism, and it is predicted that:

$\mathbf{H}_{4}$ : Perceived mindless anthropomorphism will have a positive relationship with consumer comprehension of RNPs.

Mindless anthropomorphism can be linked to another type of perceived anthropomorphism discussed within the CME context - perceived website anthropomorphism, or website socialness. Perceived website anthropomorphism is strongly linked to Social Response Theory (Moon, 2000), and is used in studies to "describe the phenomenon of users treating technology or technology interface such as websites as social actors" (Wakefield et al., 2011, p.119). Perceived website anthropomorphism refers to "the extent to which consumers detect socialness on a website" such as politeness and friendliness (Wakefield et al., 2011, p.119). Wakefield (2011) further links back to literature suggesting that perceived anthropomorphism is a mindless act (e.g. Langer, 1989; Nass and Moon, 2000); an individual's automatic reaction towards human-computer interaction is based on the heuristic aspect of the information provided (e.g. Reeves and Nass, 1996). Any interactive content enhancing visual modality results in an improved mindless anthropomorphism similar to virtual agents, as rich media can transit social cues (Wang et al., 2007)

Mindless anthropomorphism has been linked to website socialness and website socialness also has a positive effect on consumer attitude and intention (i.e. Letheren et al. 2017 ; Wakefield et al., 2011) and interactive content results in higher perceived website socialness (Wang et al. 2007). Wang et al. (2007) discovered how content interactivity enhancing visual modality (e.g. using an interactive 3D product presentation) can result in improved perceived mindless anthropomorphism, which will influence consumer attitude and purchase intention. Previous research indicates that interaction with a human-like agent also positively influences consumer attitude and intention towards the product (e.g. Choi et al., 2001; Jin, 2009; Wakefield et al., 2011). Therefore, it is hypothesized:

$\mathbf{H}_{5}$ : perceived mindless anthropomorphism will have a positive relationship with consumer attitude and purchase intention towards RNPs.

\section{Methodology}

\subsection{Research Design}

The research design is a single factor between-subject design for two separate products. The study manipulation involves anthropomorphism (mindful and mindless) within five settings of a base level (no interactivity and no anthropomorphism), low/high content interactivity conditions and static/human-like avatars conditions. Products were selected by conducting an online experiment with 50 participants in order to confirm the products to be RNPs. Informed consent was obtained for all participants in the study. In this study, a human-like image was used as the static avatar because a human-like virtual image will result in a stronger social response than a nonhuman image.

\subsection{Product selection}

To identify suitable RNPs for this study, nine RNPs were selected from various websites, where there was enough information and pictorials available online to provide a presentation. The products were tested to confirm their characteristics as RNPs, by an online experiment of 50 participants via Amazon Mechanical Turk (Mturk $)^{3}$, with the target population. Perceived product newness was measured by combining Gregan-Paxton et al.'s (2002) definition of RNPs and Hoeffler's framework that has been used in recent RNP related research (e.g. Alexander et al., 2008) (Appendix A). Gregan-Paxton et al.'s definition is related to the level of product

\footnotetext{
${ }^{3}$ www.mturk.com
} 
newness; whereas Hoeffler's framework is concerned with whether participants understand and like the product (group 1), or whether participants are aware that they need to change their behaviour in order to do new things with the product (group 2). Products that were scored highly in either group were identified and two products, which fit a similar domain were selected, namely the Dismount Washer (referred to as product 1) and the Washing Machine-in a Wardrobe (referred to as product 2). Dismount Washer is a tub for laundry that can be mounted on an energy stick. The machine uses high-pressure steam as its source for cleaning. Washing Machinin a Wardrobe is a suit cover that washes cloths while it hangs in the cupboard. The machine uses Ozone (O3) converted from Oxygen (O2) in the air (more detail on appendix A). Having two RNPs from each group will increases the validity of the findings and enhances the assumption of generalizability. Furthermore, selecting RNPs from the same category can minimize the effect of innovation characteristics on consumers' perception, through the process of diffusion of innovation.

\subsection{Experimental Conditions}

Five conditions were used in this study for both products 1 and 2: (1) Base website (low interactivity, no avatar), (2) low interactivity (low level of content interactivity, no avatar), (3) high interactivity (high level of content interactivity, no avatar), (4) low anthropomorphism (static avatar), and (5) high anthropomorphism (human-like avatar). Both static and human-like avatars were used for this study. The static avatar is a picture of the anthropomorphic avatar. The anthropomorphic avatar was purchased from sitepal ${ }^{4}$. Sitepal is a provider of online virtual agents and avatars can be purchased on an annual contract. The avatar possesses artificial intelligence and contains a general database of commands and responses. In order to customize the avatar according to the nature and purpose of this study, a focus group of academics was employed so as to develop a close-to-reality database for the human-like avatar. An email was sent to academic at a London University for the focus group and as a result sample of 6 academics were recruited. The focus group consisted of 4 male and 2 female between the ages of 20-49. They were asked to think about the questions participants within the humanlike settings could ask from the avatar, and what would be the best answers the avatar could reply with. In addition, participants were encouraged to think about any ideas that would make the human-like avatar more anthropomorphic. They suggested changing the presentation format of the human-like avatar. There were also suggestions about how the human-like avatar should start her introduction. The questions and answers extracted from the focus group were added to the existing database of the purchased avatar.

Content interactivity was implemented in the form of a 3D design of the selected RNPs for the high interactivity condition. The 3D design enabled participants to interact with the product, rotate it, zoom in/out of it, and move the model. In the low interactivity condition there were static pictures and text. Snapshots of various experimental conditions can be found in Appendix A.

\subsection{Data Collection and Sample}

Overall 556 participants contributed to this study. There was a focus group of 6 academics for the purpose of Avatar development, a sample of 50 was recruited via Mturk for measuring product newness and a total of 500 participants, 250 experimental participants for each product, were recruited via Mturk for the main experiment. Participants were randomly assigned to one of two products and one of the five experiment conditions (i.e. webpages). The website was designed using $\mathrm{Wix}^{5}$ platform for the purpose of this study. The website included 5 tabs for each product, Base interface (no interactivity, no social cue), Low interactivity, High interactivity, Low anthropomorphism and High anthropomorphism. More detail is available in Appendix A. After examining the webpage tab randomly allocated, participants were directed to the online survey, which was designed and distributed using iSurvey. Participants' demographic data consisting of gender, age, education and monthly income were gathered for all experiments (Table 1).

\footnotetext{
${ }^{4}$ www.sitepal.com

${ }^{5}$ wix.com
} 
Table 1: Demographics of Sample

\begin{tabular}{|l|l|c|c|c|}
\hline & \multicolumn{4}{|c|}{ Percentages } \\
\hline \multirow{4}{*}{ Gender } & & Total sample & Product 1 & Product 2 \\
\hline \multirow{5}{*}{ Age } & Male & 50.6 & 50.8 & 50.4 \\
\cline { 2 - 5 } & Female & 49.4 & 49.2 & 49.6 \\
\cline { 2 - 5 } & $20-29$ & 36.0 & 34.4 & 37.6 \\
\cline { 2 - 5 } & $30-39$ & 39.8 & 41 & 38.6 \\
\cline { 2 - 5 } & $40-49$ & 12.2 & 13.0 & 11.4 \\
\cline { 2 - 5 } & 50 and over & 12.0 & 12.0 & 12.0 \\
\hline \multirow{5}{*}{ Education } & less than \$999 pm & 20.6 & 20.0 & 21.2 \\
\cline { 2 - 5 } & $\$ 1000-\$ 1999$ pm & 26.4 & 22.0 & 30.8 \\
\cline { 2 - 5 } & $\$ 2000-\$ 2999$ pm & 21.0 & 20.8 & 21.2 \\
\cline { 2 - 5 } & $\$ 3000-\$ 3999$ pm & 15.8 & 17.6 & 14.0 \\
\cline { 2 - 5 } & More than \$4000 pm & 16.2 & 19.6 & 12.8 \\
\cline { 2 - 5 } & Primary School & 26.6 & 26.0 & 27.2 \\
\cline { 2 - 5 } & Secondary/high school & 48.4 & 54.8 & 42.0 \\
\cline { 2 - 5 } & Undergraduate college/university & 22.6 & 17.6 & 27.6 \\
\cline { 2 - 5 } & Graduate college/university & 1.4 & 0.8 & 2.0 \\
\cline { 2 - 5 } & PhD & & & 1.2 \\
\hline
\end{tabular}

\subsection{The Stimuli and Measures}

Data was collected via an online questionnaire. To test the hypotheses, constructs were measured using existing multi item scales to evaluate participant responses to the stimuli. The scales were all established scales extracted from related studies, though some scales were slightly altered to suit the context of the study. The questionnaire contained measures for the dependent variables of comprehension, attitude and purchase intention, followed by measures of mindless and mindful anthropomorphism. All scales can be found in Appendix B.

\subsubsection{Comprehension}

To measure comprehension, a 6-item 7-point scale developed by Feiereisen et al. (2008) was selected. The scale itself is combination of a 2-item semantic differential scale by (Phillips, 2000) and a 4-item 7-point Likert scale by Moreau et al. (2001). The KMO and Bartlett's test both support the combination of the scale items as appropriate (Feiereisen et al., 2008).

\subsubsection{Attitude}

To measure attitude, a 10-item scale developed by Voss et al. (2003) was used. The scale was deemed reliable as further studies reported a Cronbach alpha of 0.91 for the utilitarian part of the scale, and 0.89 for the hedonic part of the scale (Ogertschnig and van der Heijden, 2004). The scale was measured by a 7-point semantic differential scale.

\subsubsection{Purchase Intention}

To measure purchase intention, a 4-item 7-point Likert scale adopted from Moon et al. (2008) was used. A Cronbach alpha of 0.86 supported the reliability of the scale.

\subsubsection{Anthropomorphism}

This study is concerned with an individual's perception of anthropomorphism when dealing with different websites displaying various social cues, including content interactivity and static/human-like avatars. Kim and Sundar's (2012) mindful and mindless scale are selected for the purpose of this study, as it looks at both website and avatar factors.

In measuring anthropomorphism, both mindful and mindless anthropomorphism were considered. The mindful anthropomorphic scale consisted of three statements measured by a 10-point scale $(\alpha=.86, \mathrm{M}=15.53$, $\mathrm{SD}=5.94)$; the mindless anthropomorphism scale consisted of four items measured on a 10-point semantic differential scale $(\alpha=0.85, \mathrm{M}=24.90, \mathrm{SD}=7.25)$ (Kim and Sundar, 2012). 


\subsection{Statistical Analysis}

Confirmatory Factor Analysis (CFA) was used to test the measurement model. KMO and Bartlett's test for sphericity indicated the suitability of the data for factor analysis. Hair et al.'s (2010) stages, and model fit guidelines, for CFA were followed (see Appendix C for details) using the full data set (500 participants). According to Hair et al. (2010), three to four fit indices are usually enough to provide adequate evidence of model fit. They recommend that researchers should consider at least one incremental index (e.g., NFI), one comparative fit index (CFI), and one absolute index (e.g., GFI, AGFI,RMSEA,). A CFI larger than 0.9 and/or GFI larger than 0.9 indicate a satisfactory fit (Hair et al. 2010, Awang 2012), as do AGFI larger than 0.9 (Kline 2005). RMSEA smaller than .05 indicates a good fit, with between .05 and .08 indicating acceptable fit (Hair et al. 2010, Awang 2012).

Internal consistency was measured using Cronbach Alpha $(\alpha)$ on the dimensions extracted by factor analysis with an acceptable $\alpha$ higher than .70 (DeVellis 1991). Discriminant validity and convergence validity were measured by calculating Composite Reliability (CR>0.7), Average Variance Extracted (AVE $>.05,<\mathrm{CR}$ ), Maximum Shared Variance (MSV<AVE), Average Shared Variance (ASV<AVE) and correlations between scales being less than the square root of the AVE (Fornell and Larcker, 1981; Hair et al., 2010). Data analysis was performed using SPSS v.21 for Mac (IBM Corp, Armonk, New York).

\section{Findings}

\subsection{Confirmatory Factor analysis}

The initial measurement model fit was not acceptable $\left(\chi^{2}(314)=2720.707 \mathrm{p}=.000 ; \mathrm{CFI}=.789\right.$; GFI=.635; AGFI= .561; RMSEA=.124; Pclose $=.000)$, therefore the item loadings were examined as to improve model fit items with factor loading smaller than .5 can be eliminated (Hair et al. 2010). Items with factor loadings less than 0.5 and with the biggest modification indices were removed. This resulted in seven items being removed from the model (five out of ten items from the attitude scale, one purchase intention item, and one mindless anthropomorphism item). The final model has a good fit $\left(\chi^{2}(158)=391.026 \mathrm{p}=.000 ; \mathrm{CFI}=.971 ; \mathrm{GFI}=.925\right.$; AGFI=.90; RMSEA= .05; Pclose=.141), with all items loading significantly on their respective construct, which supports the convergent validity of the measurement items. All final scales were tested for uni-dimensionality and homogeneity. All were satisfactory. Detailed information for each scale's uni-dimensionality and homogeneity can be found in Appendix D. Final scales were re-examined in order to determine whether the measures were appropriate for further use in hypothesis testing. Bartlett's test for sphericity and KMO were performed for individual scales for the purpose of homogeneity, which all appeared to be satisfactory.

Once a suitable measurement model was established, the scales' internal consistency estimates and reliability were assessed. Table 2 shows that all the conditions necessary to demonstrate reliability, convergent and discriminant validity were met. In addition, there were no concerns regarding the normality of any of the variables (Field, 2005). Detailed information about each variable's tests of normality and histograms can be found in Appendix E.

Table 2: Reliability, Discriminant/convergence validity for final model.

\begin{tabular}{|l|l|l|l|l|l|l|l|l|l|l|}
\hline & & & & & \multicolumn{3}{|c|}{ Correlations } \\
& CR & AVE & MSV & ASV & $\alpha$ & MFA & MLA & PI & CO & AT \\
\hline Mindful Anthropomorphism (MFA) & 0.85 & 0.66 & 0.36 & 0.18 & 0.85 & $.81^{*}$ & & & & \\
\hline Mindless Anthropomorphism (MLA) & 0.92 & 0.78 & 0.36 & 0.25 & 0.91 & .60 & $.89^{*}$ & & & \\
\hline Purchase Intention (PI) & 0.94 & 0.84 & 0.28 & 0.21 & 0.94 & .38 & .49 & $.92^{*}$ & & \\
\hline Comprehension (CO) & 0.92 & 0.67 & 0.18 & 0.13 & 0.93 & .27 & .34 & .42 & $.82 *$ & \\
\hline Attitude (AT) & 0.90 & 0.64 & 0.28 & 0.21 & 0.90 & .38 & .53 & .53 & .39 & $.80^{*}$ \\
\hline
\end{tabular}

* Square root of AVE

\subsection{Mindless Anthropomorphism H1-H2}

Table 3 presents the T-test results for various conditions when evaluating mindless anthropomorphism. The findings showed a significant differences $(\mathrm{t}(98)=-3.78, \mathrm{p}=.000)$ in mindless anthropomorphism between the website with a human-like avatar (Mean $\left.{ }_{\mathrm{HAl}}=4.59, \mathrm{SD}_{\mathrm{HAl}}=1.24\right)$ and the base-line website (no human-like) $\left(\mathrm{Mean}_{\mathrm{B} 1}=3.57, \mathrm{SD}_{\mathrm{B} 1}=1.44\right)$. This was not significant for product 2 ; therefore, $\mathrm{H} 1$ is only partially supported. 
However, looking into conditions with static vs. human-like avatars, the findings indicated a significant difference $(\mathrm{t}(98)=-2.57, \mathrm{p}=.012)$ in mindless anthropomorphism between the website with static avatar $\left(\mathrm{Mean}_{\mathrm{SAl}}=3.85, \mathrm{SD}_{\mathrm{SAl}}=1.58\right)$ in comparison to human-like avatar $\left(\mathrm{Mean}_{\mathrm{HAl}}=4.59, \mathrm{SD}_{\mathrm{HAl}}=1.24\right)$ for product 1 and product $2\left(\mathrm{t}(98)=-2.16, \mathrm{p}=.033 ; \mathrm{Mean}_{\mathrm{SA} 2}=3.98, \mathrm{SD}_{\mathrm{SA} 2}=1.46 ; \mathrm{Mean}_{\mathrm{HA} 2}=4.62, \mathrm{SD}_{\mathrm{HA} 2}=1.48\right.$. This indicates that the existence of a static avatar more positively influences an individual's perceived mindless anthropomorphism.

T-test results show that there was no significant differences in mindless anthropomorphism for the website with Interactive content when compared to static avatar website for products 1 and 2 . When comparing the interactive condition with the static avatar website, no significant differences in mindless anthropomorphism was observed for product 2 , although there was a significant difference $(\mathrm{t}(98)=-2.54, \mathrm{SD}=1.36)$ between the interactive content condition $\left(\mathrm{Mean}_{\mathrm{ICl}}=3.92, \mathrm{SD}_{\mathrm{ICl}}=1.36\right)$ and human-like avatar condition $\left(\mathrm{Mean}_{\mathrm{HAl}}=4.59, \mathrm{SD}\right.$ $\left.\mathrm{HAl}_{1}=1.24\right)$ for product 1 . However, as the mean for interactive content with product 1 is lower than the other website, $\mathrm{H} 2$ is rejected.

Table 3: Test of hypotheses - Mindless Anthropomorphism manipulation

\begin{tabular}{|c|c|c|c|}
\hline Hypotheses & Conditions & $\begin{array}{l}\text { Dependent } \\
\text { Variable } \\
\end{array}$ & t-test result \\
\hline \multirow[t]{2}{*}{ H1 } & \multirow{2}{*}{$\begin{array}{l}\text { human-like avatar } \\
\text { vs. } \\
\text { No=avatar (Base) }\end{array}$} & \multirow{2}{*}{$\begin{array}{l}\text { Perceived mindless } \\
\text { Anthropomorphism }\end{array}$} & $\begin{array}{c}\text { P1: Significant }- \text { Supported } \\
\left(\mathrm{Mean}_{\mathrm{HA}}=4.59, \mathrm{SD}=1.24 ; \text { Mean }_{\mathrm{B}}=3.57\right. \\
\mathrm{SD}=1.44, \mathrm{t}(98)=-3.78, \mathrm{p}=.000)\end{array}$ \\
\hline & & & $\begin{array}{c}\text { P2: Non-significant }- \text { Rejected } \\
(\mathrm{t}(98)=-1.64, \mathrm{p}>0.05)\end{array}$ \\
\hline \multirow{2}{*}{$\mathrm{H} 1$} & \multirow{2}{*}{$\begin{array}{l}\text { Static avatar vs. } \\
\text { Human-like } \\
\text { avatar }\end{array}$} & \multirow{2}{*}{$\begin{array}{l}\text { Perceived mindless } \\
\text { Anthropomorphism }\end{array}$} & $\begin{array}{c}\text { P1: Significant }- \text { Supported } \\
\left(\text { Mean }_{\mathrm{HA}}=4.59, \mathrm{SD}=1.24 ;\right. \\
\text { Mean }_{\mathrm{SA}}=3.85, \mathrm{SD}=1.58, \mathrm{t}(98)=-2.57 \\
\mathrm{p}=.012)\end{array}$ \\
\hline & & & $\begin{array}{c}\text { P2: Significant }- \text { Supported } \\
\left(\text { Mean }_{\mathrm{HA}}=4.62, \mathrm{SD}=1.48 ;\right. \\
\operatorname{Mean}_{\mathrm{SA}}=3.98, \mathrm{SD}=1.46, \mathrm{t}(98)=-2.16, \\
\mathrm{p}=.033)\end{array}$ \\
\hline \multirow[t]{2}{*}{$\mathrm{H} 2$} & \multirow{2}{*}{$\begin{array}{l}\text { Interactive } \\
\text { content vs. } \\
\text { Static or human- } \\
\text { like avatar }\end{array}$} & \multirow{2}{*}{$\begin{array}{l}\text { Perceived mindless } \\
\text { Anthropomorphism }\end{array}$} & $\begin{array}{c}\text { P1 (Static avatar }) \text { : Non-significant }- \\
\text { Rejected } \\
(\mathrm{t}(98)=.237, \mathrm{p}>0.05) \\
\text { Pl (human-like avatar }) \text { : Significant } \\
(\text { mean reversed })-\text { Rejected } \\
\left(\mathrm{Mean}_{\mathrm{HA}}=4.59, \mathrm{SD}=1.24 ; \text { Mean }_{\mathrm{IC}}=3.92\right. \\
\mathrm{SD}=1.36, \mathrm{t}(98)=-2.54, \mathrm{p}=.013)\end{array}$ \\
\hline & & & $\begin{array}{c}P 2 \text { (Static avatar }) \text { : Non-significant }- \\
\text { Rejected } \\
(\mathrm{t}(98)=-.494, \mathrm{p}>0.05) \\
\text { P2 (human-like avatar }) \text { : Non-significant } \\
- \text { Rejected } \\
(\mathrm{t}(98)=-161, \mathrm{p}>0.05)\end{array}$ \\
\hline
\end{tabular}

\subsection{Mindful Anthropomorphism $\mathrm{H3}$}

Looking at mindful anthropomorphism (Table 4), the results indicated that there are no significant differences observed in individual's mindful anthropomorphism between the base condition when compared to the humanlike avatar condition or the interactive content condition for either product. Therefore, H3 is rejected. 
Table 4: Test of hypotheses - Mindful Anthropomorphism manipulation

\begin{tabular}{|c|c|c|c|}
\hline Hypotheses & Conditions & Dependent Variable & t-test result \\
\hline \multirow{2}{*}{$\mathrm{H} 3$} & \multirow{2}{*}{$\begin{array}{l}\text { No avatar-No interactive content } \\
\text { (Base) vs. Human like avatar }\end{array}$} & \multirow{2}{*}{$\begin{array}{l}\text { Perceived mindful } \\
\text { Anthropomorphism }\end{array}$} & $\begin{array}{c}P 1: \text { Non- } \\
\text { significant }- \text { Rejected } \\
(\mathrm{t}(98)=-.436, \\
\mathrm{p}>0.05)\end{array}$ \\
\hline & & & $\begin{array}{c}P 2: \text { Non- } \\
\text { significant }- \text { Rejected } \\
(\mathrm{t}(98)=.882, \\
\mathrm{p}>0.05)\end{array}$ \\
\hline \multirow{2}{*}{ H3 } & \multirow{2}{*}{$\begin{array}{l}\text { No avatar-No interactive content } \\
\text { (Base) vs. Interactive content }\end{array}$} & \multirow{2}{*}{$\begin{array}{l}\text { Perceived mindful } \\
\text { Anthropomorphism }\end{array}$} & $\begin{array}{c}P 1: \text { Non- } \\
\text { significant }- \text { Rejected } \\
(\mathrm{t}(98)=.084 \\
\mathrm{p}>0.05)\end{array}$ \\
\hline & & & $\begin{array}{c}P 2: \text { Non- } \\
\text { significant }- \text { Rejected } \\
(\mathrm{t}(98)=.170, \\
\mathrm{p}>0.05)\end{array}$ \\
\hline
\end{tabular}

\subsection{Correlation between dependent variables $\mathrm{H} 4-\mathrm{H} 5$}

As per Table 5, there is a moderate (Dancey and Reidy, 2004) positive correlation between perceived mindless anthropomorphism and comprehension $(\mathrm{r}=0.43, \mathrm{~N}=250, \mathrm{p}=.000)$ for product 1 , and a weak positive correlation $(\mathrm{r}=0.32, \mathrm{~N}=250, \mathrm{p}=.000)$ for product 2 . The correlation was moderate for both products 1 ( $\mathrm{r}=0.61$, $\mathrm{N}=250, \mathrm{p}=.000)$ and $2(\mathrm{r}=0.47, \mathrm{~N}=250, \mathrm{p}=.000)$ between perceived mindless anthropomorphism and attitude. There was a moderate positive correlation observed between perceived mindless anthropomorphism and purchase intention for product $1(\mathrm{r}=0.53, \mathrm{~N}=250, \mathrm{p}=.000)$ and product $2(\mathrm{r}=0.56, \mathrm{~N}=250, \mathrm{p}=.000)$. Therefore, both $\mathrm{H} 4$ and H5 are supported.

Table 5: Test of hypotheses - Correlation between dependent variables

\begin{tabular}{|c|c|c|c|}
\hline Hypotheses & Observing & Dependent Variable & Result \\
\hline \multirow{2}{*}{$\mathrm{H} 4$} & \multirow{2}{*}{$\begin{array}{l}\text { Correlation between perceived mindless } \\
\text { anthropomorphism and comprehension }\end{array}$} & \multirow{2}{*}{$\begin{array}{l}\text { Perceived mindless } \\
\text { Anthropomorphism }\end{array}$} & $\begin{array}{c}\text { Pl: Moderate } \\
\text { Positive Correlation - } \\
\text { Supported } \\
(\mathrm{r}=0.43, \mathrm{~N}=250, \\
\mathrm{p}=.000)\end{array}$ \\
\hline & & & $\begin{array}{l}P 2: \text { Weak Positive } \\
\text { Correlation - } \\
\text { Supported } \\
(\mathrm{r}=0.32, \mathrm{~N}=250, \\
\mathrm{p}=.000)\end{array}$ \\
\hline \multirow{2}{*}{ H5 } & \multirow{2}{*}{$\begin{array}{l}\text { Correlation between perceived mindless } \\
\text { anthropomorphism and attitude }\end{array}$} & \multirow{2}{*}{$\begin{array}{l}\text { Perceived mindless } \\
\text { Anthropomorphism }\end{array}$} & $\begin{array}{c}\text { Pl: Moderate } \\
\text { Positive Correlation }- \\
\text { Supported } \\
(\mathrm{r}=0.61, \mathrm{~N}=250, \\
\mathrm{p}=.000)\end{array}$ \\
\hline & & & $\begin{array}{c}\text { P2: Moderate } \\
\text { Positive Correlation - } \\
\text { Supported } \\
(\mathrm{r}=0.47, \mathrm{~N}=250, \\
\mathrm{p}=.000)\end{array}$ \\
\hline
\end{tabular}




\begin{tabular}{|c|c|c|c|}
\hline Hypotheses & Observing & Dependent Variable & Result \\
\hline \multirow{2}{*}{ H5 } & \multirow{2}{*}{$\begin{array}{c}\text { Correlation between perceived mindless } \\
\text { anthropomorphism and purchase } \\
\text { intention }\end{array}$} & \multirow{2}{*}{$\begin{array}{l}\text { Perceived mindless } \\
\text { Anthropomorphism }\end{array}$} & $\begin{array}{c}\text { Pl: Moderate } \\
\text { Positive Correlation - } \\
\text { Supported } \\
(\mathrm{r}=0.53, \mathrm{~N}=250, \\
\mathrm{p}=.000)\end{array}$ \\
\hline & & & $\begin{array}{c}\text { P2: Moderate } \\
\text { Positive Correlation - } \\
\text { Supported } \\
(\mathrm{r}=0.56, \mathrm{~N}=250, \\
\mathrm{p}=.000)\end{array}$ \\
\hline$* P 1: F$ & 1 (Dismount Washer); P2: Produ & ing Machine in $W c$ & \\
\hline
\end{tabular}

\section{Discussion}

Empirical evidence from this study contributes to the body of knowledge in the area of human interaction with Social Cues at the time of RNP promotion. The study looked at anthropomorphism as a construct divided into mindless and mindful (Kim and Sundar 2012), as opposed to one collective conception, in order to address the inconsistency of the previous literature in observing whether human-like avatars can result in a better sense of anthropomorphism (e.g. Mori, 1970; Nowak and Biocca, 2003). Findings indicate that some social cues result in enhanced perceived mindless anthropomorphism; for example, human-like avatars are mindlessly perceived as more anthropomorphic in comparison to static avatars (for both products) or no avatars (for one product) when promoting RNPs. This is in line with previous studies on perceived anthropomorphism (Araujo 2018) and the increased feelings of social presence when using human-like avatars (Burgoon et al. 2009; Lee and Nass 2003). However, product type and characteristics played an important role due to the inconsistency of the findings, as product 2 was not perceived mindlessly higher when a human-like avatar was compared with no-avatar. This can be due to the difference in aesthetics between products, where product 1 includes more colour than product 2 , or from perhaps the inclusion of a human figure in product 1 base condition in comparison to no human figure in product 2 base condition.

The findings also revealed that interactive content is not mindlessly perceived as more anthropomorphic in comparison to avatars; this runs contrary to previous academic literature that expresses how content interactivity creates website socialness and, as a result, improves perceived anthropomorphism (Liu and Shrum, 2002; Wakefield et al., 2011). This difference from the existing literature might be due to the unique nature of RNPs. That is, RNPs are generally high-involvement products that require high learning investment on the part of the consumer, hence social cues may present themselves as a distraction. This paper extends Kim and Sundar's (2012) findings to RNPs, concerning the effects of mindless vs. mindful anthropomorphism within CMEs. As is evident, participants did not report any significant differences in mindful anthropomorphism when exposed to various levels of social cues, whereas mindless anthropomorphism was significantly different in some conditions. This indicates that RNP characteristics do not have any impact upon the existing understanding of mindful anthropomorphism.

While a positive moderate correlation between perceived mindless anthropomorphism and comprehension, attitude and purchase intention was apparent with product 1 , this was not the case with product 2 . There was a weak positive correlation between perceived mindless anthropomorphism and comprehension for product 2 which can be again due to the characteristics of product 2 and its presentation format. As the study used publicly available RNP information, product 1 was explained with more visuals than product 2; hence the findings indicate not only the importance of RNP characteristics on social cues perception in CMEs, but also on the information presentation format. RNPs have unique characteristics, not only requiring more learning and cognitive effort to understand, but also necessitating that consumers process product information when initially interacting with the product. It is thus crucial for practitioners to design platforms that include the most effective interface and level of social cues, to facilitate consumers understanding of RNPs at the time of interaction. This 
research indicates that human-like avatars are able to improve an individual's perceived mindless anthropomorphism and consequently enhance their learning, attitude and intention towards RNPs. Given this, human-like avatars can be included in RNP online promotional interfaces. Future studies should consider whether there are specific characteristics of RNPs that lead to these relationships and inconsistencies observed in RNPs used in this study.

\subsection{Limitation and Future Research}

A limitation of this study is the use of limited number of RNPs. The products selected by participants as most suitable were both utilitarian. This indicates that RNP characteristics need to be more closely examined when considering the generalisability of the results, and definitely points towards exploring the impact of anthropomorphism on other types of RNPs (e.g., hedonic, experiential, goods/services). While the results from the two products were generally consistent, the impact of product characteristics on the relationships explored in this study need to be more fully 'unpacked'. Future research can also seek to investigate innovation attributes identified by Rogers (2003), such as relative advantage, compatibility, complexity, trialability and observability, as they may have an impact on individual's anthropomorphism perception, learning and attitude towards RNPs presented in CMEs with various levels of social cues. Also domain limitation should be taken into consideration and RNPs from other domains should be considered in future studies. This is due to individuals differences of involvement based on their domain of interest which can impact the findings of this study. Product presentation formats, such as use of visuals and colours needs to be explored further as well.

In conclusion, this paper sought to understand the impact of various social cues on individuals' perceived anthropomorphism while interacting with RNP related information online. Overall, it found that a website with a human-like avatar is the best interface for promoting RNPs as it results in an enhanced mindless anthropomorphism and consequently an improved understanding and more positive attitudes and purchase intentions. Nevertheless questions remain concerning product characteristics and information presentation format and content, and perceived innovation attributes, and whether these play a role in the inconsistency showed in the findings of this study. 


\section{Reference}

Abbattista, F., Anderson, V., Anderson, H.K., Lops, P. and Sameraro, G. (2002) Evaluating Virtual Agents for E-Commerce. Paper presented at First International Joint Conference on AAMAS, Bologna, Italy.

Alexander, D.L., Lynch , J.G. and Wang, Q. (2008) As Time Goes By : Do Cold Feet Follow Warm Intentions for Really New Versus Incrementally New Products? Journal of Marketing Research, 45 (3), 307-319.

Araujo, T. (2018) Living up to the chatbot hype: The influence of anthropomorphic design cues and communicative agency framing on conversational agent and company perceptions, Computers in Human Behavior, 85

Awang, Z. (2012). Structural equation modeling using AMOS graphic. Penerbit Universiti Teknologi MARA Publication Centre (UPENA).

Bahorsky, R., Graber, J. and Mason, S. (1998) Official Internet Dictionary: A Comprehensive Reference for Professionals. Rockville MD: Government Institutes.

Bandura, A. (1977) Social Learning Theory. General Learning Press.

Bartneck, C., Croft, E. and Zoghbi, S. (2009) Measuring the anthropomorphism, animacy, likeability, perceived intelligence and perceived safety of robots. International Journal of Social Robotics, 1(1), 71-81.

Bente, G., Rüggenberg S., Kramer, N. and Eschenburg F. (2008) Avatar-Mediated Networking: Increasing Social Presence and Interpersonal Trust in Net-Based Collaborations. Human Communication Research, 34(2), 287-318.

Bennett D.E. and Thompson P. (2016) Use of Anthropomorphic Brand Mascots for Student Motivation and Engagement: A Promotional Case Study With Pablo the Penguin at the University of Portsmouth Library. New Review of Academic Librarianship, 22(2)

Bickart, B. and Schindler, R.M. (2001) Internet forums as influential sources of consumer information. Journal of Interactive Marketing, 15(3), 31-40.

Brandt, D.A. (1997) Constructivism: teaching for understanding of the Internet. Communications of the ACM, 40(10), 112-117.

Burgoon, J. K., Twitchell, D. P., Jensen, M. L., Meservy, T. O., Adkins, M., Kruse, J., et al. (2009). Detecting Concealment of Intent in Transportation Screening: A Proof of Concept. [Electronic version]. Intelligent Transportation Systems, IEEE Transactions on, 10(1), 103-112.

Cassell, J., Sullivan, J., Prevost, S. and Churchill, E. (2000) Embodied Conversational Agents. Cambridge: MIT Press.

Castano, E. and Giner-Sorolla, R. (2006) Not quite human: Infra-humanization as a response to collective responsibility for intergroup killing. Journal of Personality and Social Psychology, 90, 804-818.

Chaiken, S. (1987) The heuristic model of persuasion IN: Zanna, M.P., Olson, J.M. and Herman, C.P. (eds.) Social influence: The Ontario Symposium (pp 3-39). Hillsdale, NJ: Erlbaum,

Cheng Yi,Zhenhui (Jack) Jiang \&Izak Benbasat (2015) Enticing and Engaging Consumers via Online Product Presentations: The Effects of Restricted Interaction Design, Journal of Management Information Systems, 31(4)

Choi, Y.K., Miracle, G.E. and Biocca, F. (2001) The Effects of Anthropomorphic Agents on Advertising Effectiveness and the Mediating Role of Presence. Journal of Interactive Advertising, 2(1), 3-21.

Chung, H. and Zhao, X. (2004) Effects of Perceived Interactivity on Web Site Preference and Memory: Role of Personal Motivation. Journal of Computer-Mediated Communication, 10(1)

Das G. Varshneva, G. (2017) Consumer emotions: Determinants and outcomes in a shopping mall, Journal of Retailing and Consumer Services

De Melo, Celso .M. Gratch, J. and Carnevale, Peter J. (2014) Humans vs. Computers: Impact of Emotion Expressions on People's Decision Making, IEEE Transactions on Affective Computing, 6(2)

Dehn, D. and Van Mulken, S. (2000) The Impact of Animated Interface Agents: A Review of Empirical Research. International Journal of Human-Computer Studies, 52(1), 1-22.

DeVellis, R. F. (2012). Scale development: Theory and application. Newbury Park, CA: Sage

Dereli, DD. (2015) Innovation management in global competition and competitive advantage, Procedia-Social and behavioral sciences, 193, 1365-1370

Donath, J. (2007) Virtually Trustworthy. Science, 317 (5834), 53-54. 
Etemad-Sajadi, R. (2016) The impact of online real-time interactivity on patronage intention: The use of avatars, Computers in Human Behavior, 61, 227-232

Feiereisen, S. (2009) Consumer Response to Really New Products: Examining the Impacts of Learning Strategies and Presentation Formats on Product Comprehension and Attitude Formation, Doctor of Philosophy, Aston University, UK.

Feiereisen, S., Wong, V. and Broderick, A.J. (2008) Analogies and Mental Simulations in Learning for Really New Products: The Role of Visual Attention. Journal of Product Innovation Management, 25 (6), 593-607.

Field, A. (2005) Discovering Statistics Using SPSS, 2 ed. Thousand Oaks, CA: SAGE Publications.

Fornell, C. and Larcker, D.F. (1981) Evaluating Structural Equation Models with Unobservable Variables and MeasurementError. Journal of Marketing Research, 28, 39-50.

Fox, J., Ralston, R. A., Cooper, C. K., \& Jones, K. A. (2015). Sexualized avatars lead to women's selfobjectification and acceptance of rape myths. Psychology of Women Quarterly, 39, 349-362.

Franceschi, K., Lee, R.M., Zanakis, S.H. and Hinds, D. (2009) Engaging Group E-Learning in Virtual Worlds. Journal of Management Information Systems, 26 (1), 73-100.

Gammoh, Bashar S. Jiménez, Fernando R. and Wergin , Fernando R. (2018) Consumer Attitudes Toward Human-Like Avatars in Advertisements: The Effect of Category Knowledge and Imagery, International Journal of Electronic Commerce, 22(3)

Gong, L. (2008) How social is social responses to computers? The function of the degree of anthropomorphism in computer representations. Computers in Human Behavior, 24 (4), 1494-1509.

Gong, L. and Lai, J. (2003) To mix or not to mix synthetic speech and human speech? Contrasting impact on judge-rated task performance versus self-rated performance and attitudinal responses. International Journal of Speech Technology, 6, 123-131.

Goodman, J.K., Cryder, C.E. and Cheema, A. (2013) Data Collection in a Flat World: The Strengths and Weaknesses of Mechanical Turk Samples. Journal of Behavioral Decision Making, 26 (3), 213-224.

Gregan-Paxton, J., Hibbard, J.D., Brunel, F.F. and Azar, P. (2002) So That's What That Is: Examining the Impact of Analogy on Consumers' Knowledge Development for Really New Products. Psychology and Marketing, 19 (6), 533-550.

Groom, V., Nass, C., Chen, T., Nelson, A., Scarborough, J.K. and Robles, E. (2009) Evaluating the effects of behavioural realism in embodied agents. International Journal of Human-Computer Studies, 67 (10), 842 849.

Guttentag, D.A. (2010) Virtual reality: Applications and implications for tourism. Tourism.Management, 31 (5), 637-651.

Ha, L. and James, E.L. (1998) Interactivity Reexamined: A Baseline Analysis of Early Business Web Sites. Journal of Broadcasting and Electronic Media, 42 (4), 456-463.

Hair, J.F., Black, W.C., Bebin, B.J., Anderson, R.E. (2010) Multivariate Data Analysis, 7 ed. New Jersey:: Prentice Hall.

Hoeffler, S. (2003) Measuring Preferences for Really New Products. Journal of Marketing Research, 40 (4), 406-420.

Hoeffler S. Herzenstein M. (2015) Optimal Marketing for Really New Products. In Posavac S. (ed) Cracking the code, Leveraging Consumer Psychology to Drive Profitability. (pp 21-45), Routledge

Holzwarth, M., Janiszewski, C. and Neumann, M.M. (2006) The Influence of Avatars on Online Consumer Shopping Behavior. Journal of Marketing, 70 (4), 19-36.

Isbister, K. and Nass, C. (2000) Consistency of personality in interactive characters: verbal cues, non-verbal cues, and user characteristics. International Journal of Human-Computer.Studies, 53 (2), 251-267.

Jin, S.A. (2009) Modality Effects in Second Life: The Mediating Role of Social Presence and the Moderating Role of Product Involvement. CyberPsychology and Behaviour, 12.

Kai Li, Huynh Van Nguyen, T.C.E. Cheng, Ching-I Teng, (2018) How do avatar characteristics affect avatar friendliness and online gamer loyalty? Perspective of the theory of embodied cognition, Internet Research, 28(4), 1103-1121

Kang, S. and Gratch, J. (2014) Exploring Users' Social Responses to Computer Counseling Interviewers' Behavior. Computers in Human Behavior, 34, 120-130. 
Kang, H. Kim, K.J. (2020) Feeling connected to smart objects? A moderated mediation model of locus of agency, anthropomorphism, and sense of connectedness, International Journal of Human-Computer Studies, $133,45-55$

Keeling, K.A., Mcgoldrick, P.J. and Beatty, S. (2010) Avatars as salespeople: communication style, trust, and intentions. Journal of Business Research, 63 (8), 793-800.

Kim, J. and Mcmillan, S.J. (2008) Evaluation of Internet advertising research: a bibliometric analysis of citations from key sources. Journal of Advertising, 37 (1), 99-112.

Kim, Y. and Sundar, S.S. (2012) Anthropomorphism of computers: Is it mindful or mindless? Computers in Human Behavior, 28 (1), 241-250.

Kunda, Z. (1999) Social cognition: Making sense of people. Cambridge, MA. MIT Press.

Langer, E.J. (1989) Mindfulness. Reading: Addison-Wesley.

Lee, K.M. and Nass, C. (2003) Designing social presence of social actors in human computer interaction. Paper presented at SIGCHI conference on Human factors in computing systems, Lauderdale, Florida, USA.

Lester, J.C., Barlow, S.T., Converse, S.A., Stone, B.A., Kahler, S.E. and Bhogal, R.S. (1997) The Persona Effect: Affective Impact of Animated Pedagogical Agents CHI '97, Atlanta, GA. ACM Press,, 359-366.

Letheren, Kate \& Martin, Brett A.S. \& Jin, Hyun Seung, (2017) Effects of personification and anthropomorphic tendency on destination attitude and travel intentions, Tourism Management, 62(C), 65-75.

Li, K., Nguyen, H.V., Cheng, T.C.E., and Teng, C.I. (2018). How do avatar characteristics affect avatar friendliness and online gamer loyalty? Perspective of the theory of embodied cognition. Internet Research, 28(4), 1103-1121.

Liew T.W., Tan S.M., Ismail H.(2017) Exploring the effects of a non-interactive talking avatar on social presence, credibility, trust, and patronage intention in an e-commerce website, Human-centric Computing and Information Sciences, 7(42)

Liu, Y. and Shrum, L. (2002) What is interactivity and is it always such a good thing? Implications of definition, person and situation for the influence of interactivity on advertising effectiveness. Journal of Advertising, 4, 53-64

Lowrey, T.M. (1991) The Use cf Diffusion Theory in Marketing: A Qualitative Approach to Innovative Consumer Behavior. Advances in Consumer Research, 18.

Mayer, R.E. (1997) Multimedia learning: Are we asking the right questions. Educational Psychologist, 32, 1-19.

Mengxiang Li, Kwok-Kee Wei Giri Kumar Tayic Chuan-Hoo Tan (2016) The moderating role of information load on online product presentation. Information \& Management, 53(4), 467-480

McBreen, H.M. and Jack, M.A. (2001) Experimental Assessment of Effectiveness of Synthetic Personae for Multi-Modal E-Retail Applications 4th International Conference on Autonomous Agents, Barcelona,. 3945.

Mimoun, M.S., Poncin, I. and Garnier, M. (2012) Case study-Embodied virtual agents: An analysis on reasons for failure. Journal of Retailing and Consumer Services, 19(6), 605-612.

Moon, Y. (2000) Intimate Exchanges: Using Computers to Elicit Self-Disclosure from Consumers. Journal of Consumer Research, 26(4), 323-339.

Moreau, C.P., Lehmann, D.R. and Markman, A.B. (2001) Entrenched Knowledge Structures and Consumer Response to New Products. Journal of Marketing Research, 38(1), 14-29.

Moreno, R. and Mayer, R. (2007) Interactive Multimodal Learning Environments. Educational Psychology Review, 19(3), 309-326.

Mori, M. (1970) The uncanny valley. Energy, 7(4), 33-35.

Mull I., Wyss, J. Moon, E. Lee, S.E (2015) An exploratory study of using 3D avatars as online salespeople: The effect of avatar type on credibility, homophily, attractiveness and intention to interact, Journal of Fashion Marketing and Management, 19(2), 154-168

Nass, C. and Brave, S.B. (2005) Wired for Speech: How Voice Activates and Advances the Human-Computer Relationship. Cambridge, MA.: MIT Press.

Nass, C. and Carney, P. (1999) Are People Polite to Computers? Responses to Computer-Based Interviewing Systems. Journal of Applied Social Psychology, 29 (5), 1093-1110.

Nass, C. and Moon, Y. (2000) Machines and mindlessness: Social responses to computers. Journal of Social Issues, 56 (1), 81-103. 
Nass, C. and Steuer, J. (1993) Voices, Boxes, and Sources of Messages. Human Communication Research, 19 (4), 504-527.

Nowak, K.L. (2004) The Influence of Anthropomorphism and Agency on Social Judgment in Virtual Environments. Journal of Computer Mediated Communication, 9 (2).

Nowak, K.L. and Biocca, F. (2003) The effect of the agency and anthropomorphism on users' sense of telepresence, copresence, and social presence in virtual environments. Presence: Teleoperators and Virtual Environments, 12, 481-494.

Nowak, K.L., Hamilton, M.A. and Hammond Chelsea, C. (2008) The Effect of Viewer Perceptions of Avatar Anthropomorphism and Realism on Judgments of Credibility and Homophily, and Avatar Choice. 11th Annual International Workshop on Prfddesence, Padova.

Nowak, K.L. Rauh, C. (2005) The Influence of the Avatar on Online Perceptions of Anthropomorphism, Androgyny, Credibility, Homophily, and Attraction. Journal of Computer-Mediated Communication, 11, $153-178$.

Ogertschnig, M. and Van Der Heijden, H. (2004) A short-form measure of attitude towards using a mobile information service. IN: Tan, Y.H. and Vogel, D. (eds.) Proceedings of the 17th Bled Electronic Commerce conference. Bled.

Phillips, B.J. (2000) The Impact of Verbal Anchoring on Consumer Response to Image Ads. Journal of Advertising, 29 (1), 15-24.

Posard Marek N. Rinderknecht, R.G. (2015) Do people like working with computers more than human beings? Computers in Human Behavior, 51, 232-238

Powers, A. and Kiesler, S. (2006) The advisor robot: tracing people's mental model from a robot's physical attributes. Paper presented at Proceedings of the 1st ACM SIGCHI/SIGART conference on Human-robot interaction, Salt Lake City, Utah, USA.

Ratneshwar, S. and Chaiken, S. (1991) Comprehension's Role in Persuasion: The Case of Its Moderating Effect on the Persuasive Impact of Source Cues. Journal of Consumer Research, 18 (1), 52-62.

Redmond, W.H. (2002) The Potential Impact of Artificial Shopping Agents in E-Commerce Markets. Journal of Interactive Marketing, 16 (1), 56-66.

Reeves, B. and Nass, C. (1996) The Media Equation: How People Treat Computers, Televisions, and New Media Like Real People and Places New York: Columbia University Press.

Robinson, H., Wysocka, A. and Hand, C. (2007) Internet advertising effectiveness: the effect of design for clickthrough rates for banner ads. International Journal of Advertising, 26 (4), 527-541.

Rogers, E. (2003) Diffusion of innovations, 5 ed. New York: NY: Free Press.

Steuer, J. (1992) Defining Virtual Reality: Dimensions Determining Telepresence. The Journal of Communication, 42 (4), 73-93.

Slade, E., Dwivedi, Y, Piercy, N. Williams, M. (2015) Modeling Consumers' Adoption Intentions of Remote Mobile Payments in the United Kingdom : Extending UTAUT with Innovativeness, Risk, and Trust. Psychology and Marketing, 32(8), 860-873.

Sundar, S.S. and Nass, C. (2000) Source orientation in human-computer interaction: Programmer, networker, or independent social actor? Communication Research, 27, 683-703.

Tang, J. Zhang, P. (2018)The impact of atmospheric cues on consumers' approach and avoidance behavioral intentions in social commerce websites, Computers in Human Behavior, 105729

$\mathrm{Tu}, \mathrm{C} . \mathrm{-H}$. (2000) On-line learning migration: from social learning theory to social presence theory in a CMC environment. Journal of Network and Computer Applications, 23(1), 27-37.

Van Noort, G. (2012) Interactivity in Brand Web Sites: Cognitive, Affective, and Behavioural Responses Explained by Consumers' Online Flow Experience. Journal of Interactive Marketing, 26 (4), 223-234.

Voss, K.E., Spangenberg, E.R. and Grohmann, B. (2003) Measuring the Hedonic and Utilitarian Dimensions of Consumer Attitude. Journal of Marketing Research, 40 (3), 310-320.

Wakefield, R.L., Wakefield, K.L., Baker, J. and Wang, L.C. (2011) How website socialness leads to website use. European Journal of Information Systems, 20, 118-132.

Wallace, W. (1983) Principles of Scientific Sociology. New York: Aldine.

Walther J B.Van Der Heide B. Ramirez A Jr. Burgoon J K and Pena J. (2015) Interpersonal and Hyperpersonal Dimensions of Computer-mediated Communication In Sundar S. (ed) The handbook of the psychology of communication technology.Wiley Blackwell 
Wang, L., Baker, J., Wagner, J.A. and Wakefield, K. (2007) Can a Retail Web Site Be Social? Journal of Marketing, 71 (3), 143-157.

Waytz, A., Cacioppo, J.T. and Epley, N. (2014) Who Sees Human? The Stability and Importance of Individual Differences in Anthropomorphism. Perspective Psychology Science, 5 (3), 219-232.

$\mathrm{Xu}, \mathrm{K}$. Lombard, M. (2017) Persuasive Computing: Feeling Peer Pressure from Multiple Computer Agents, Computers in Human Behavior, 74, 152-162

Zhang, D., Zhou, L., Briggs, R.O. and Nunamaker Jr, J.F. (2006) Instructional video in e-learning: Assessing the impact of interactive video on learning effectiveness. Information and Management, 43 (1), 15-27. 


\section{Appendices}

Appendix A

Base website for product 1

Icts2 I LMR $x+$

isk... i... isurvey - Online ... B Associate Lecture...

\section{Dismount Washer, Wash \& Go Laundry}

The Dismount washer combines the laundry basket and washing machine. It is a compact and stylish capsule that takes up very little space and can be hanged on the wall for enhanced interior aesthetics. The dirty laundry unit is placed on a wall mointable motor, or 'energy stick', that dispenses steam to aid the deansing process.
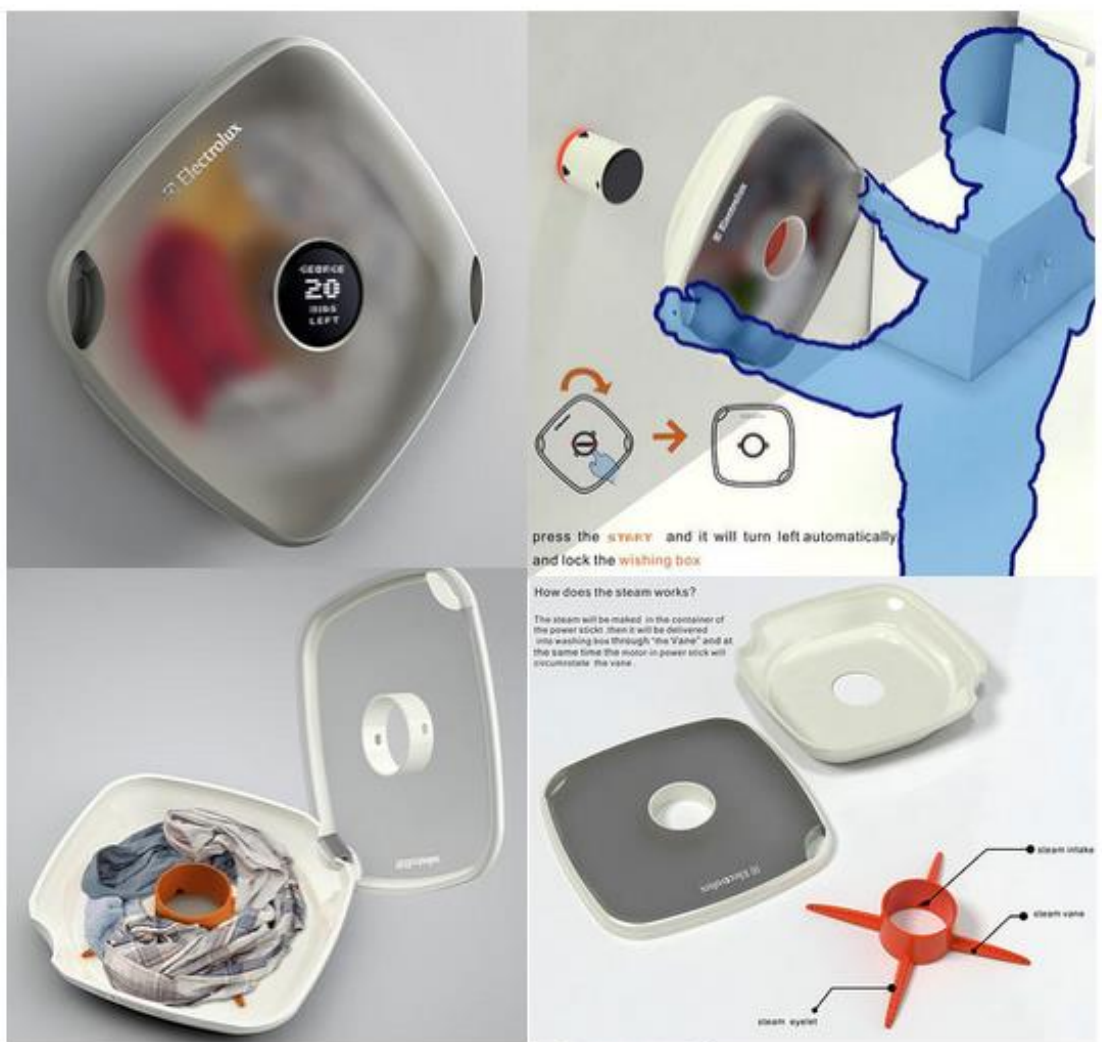

and lock the withing tiox

How coes ine steam woen?

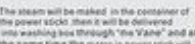

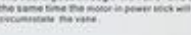
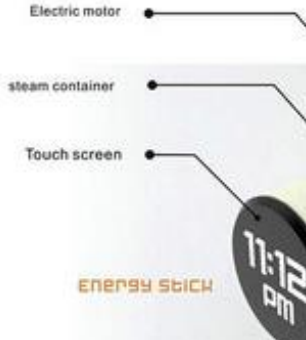

the lock tor the wasting oo
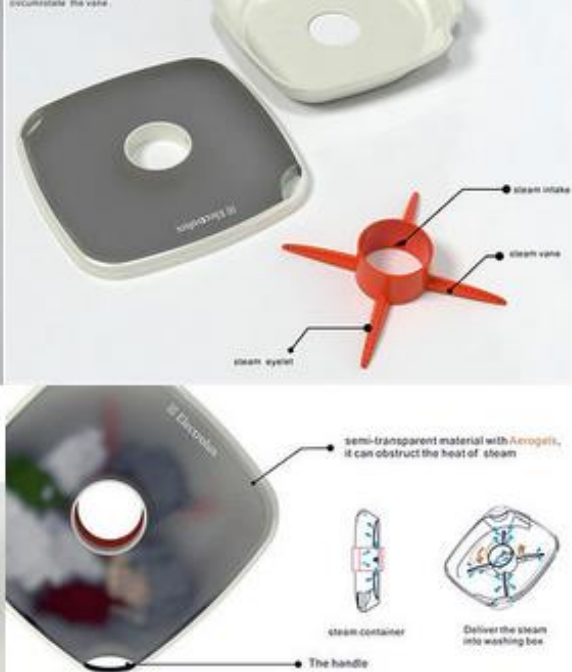

Low Interactivity for product 2 


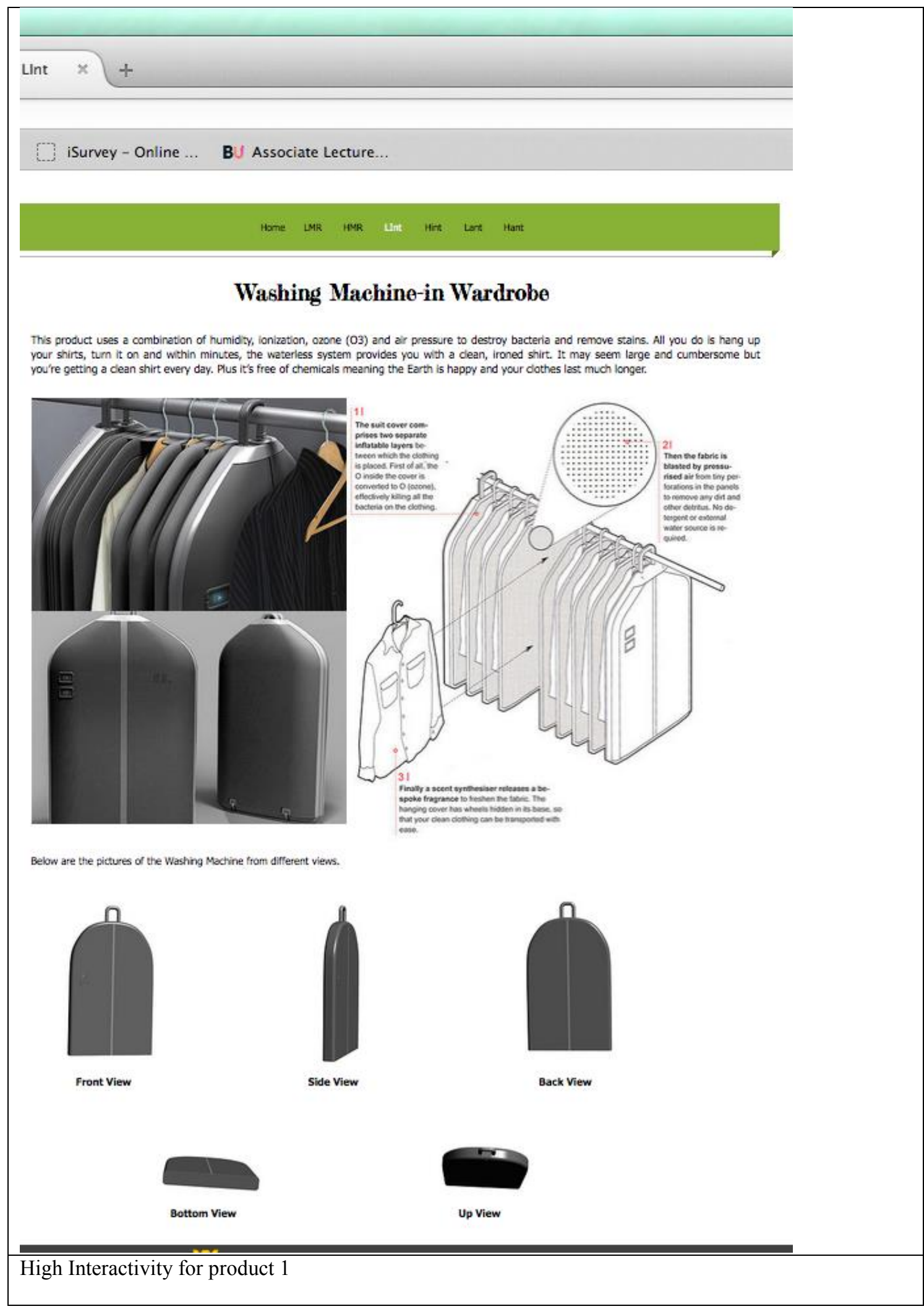




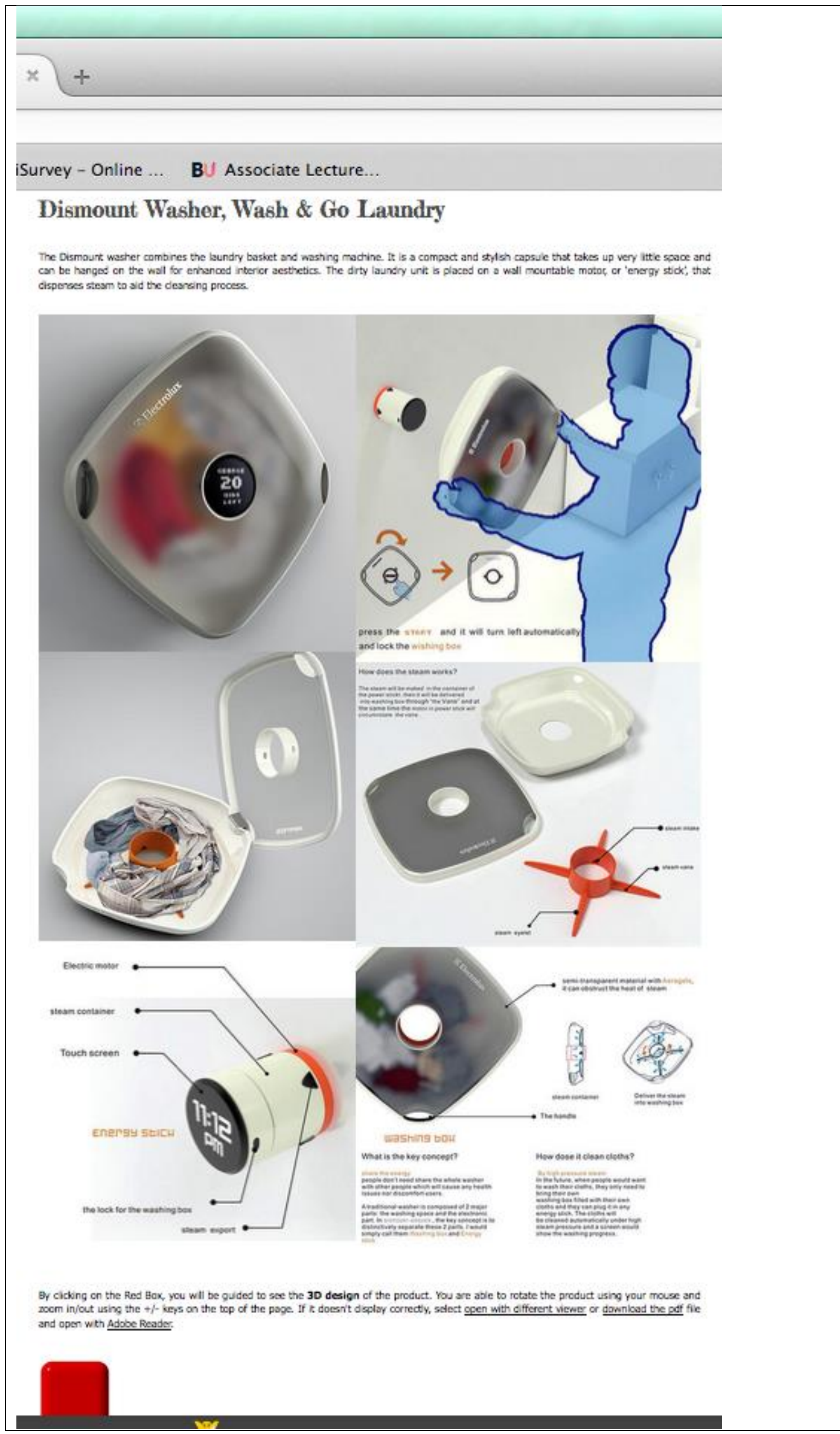




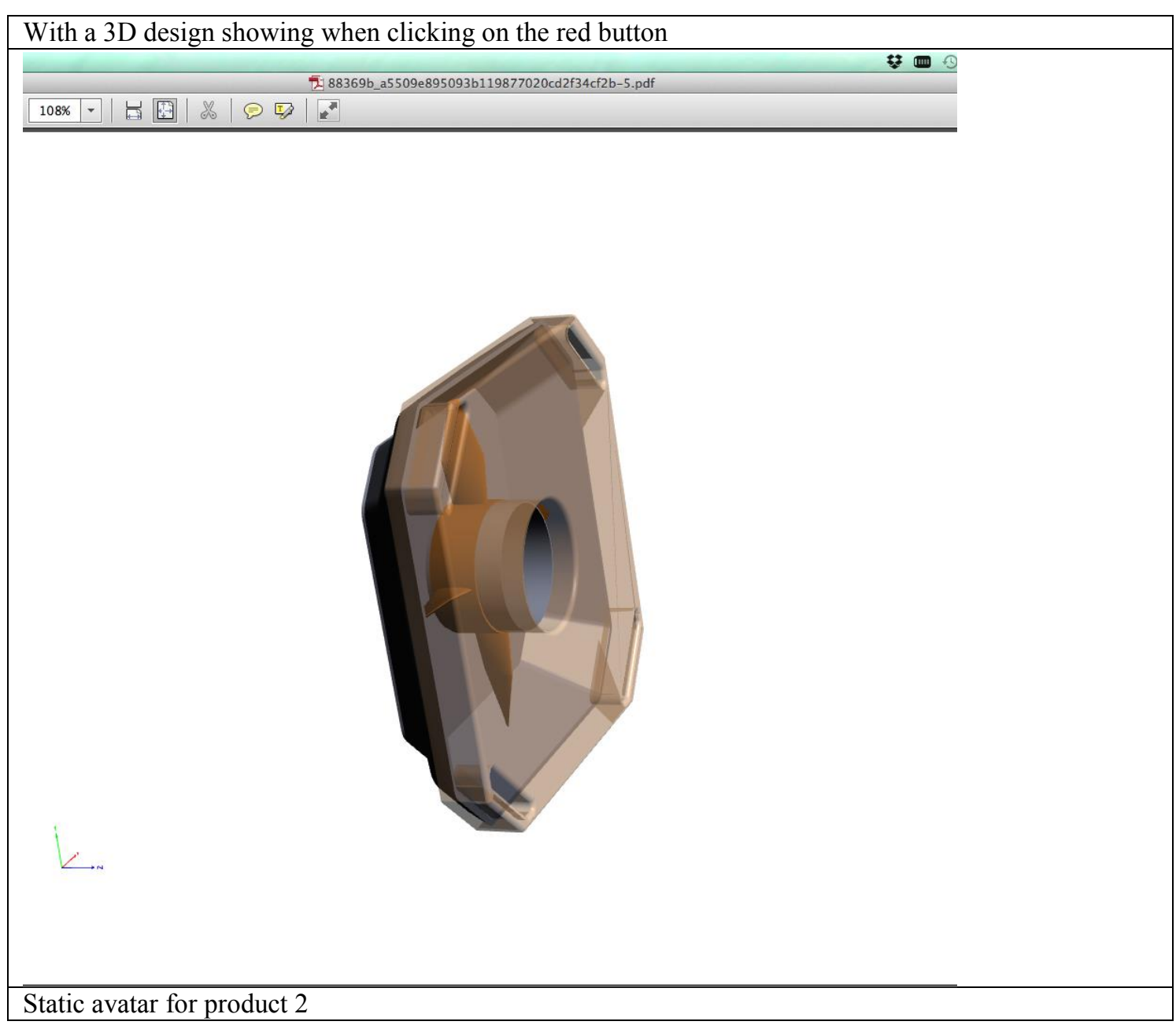




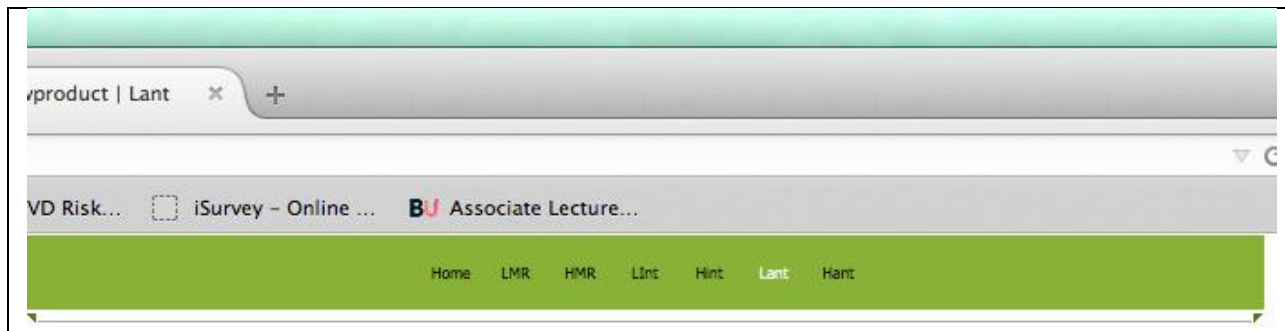

\section{Washing Machine-in Wardrobe}

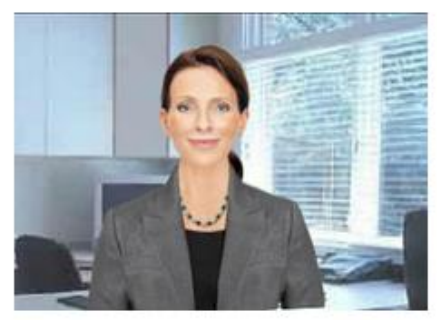

Hello, I am Julie. I want to talk about the Washing Machine in a Wardrabe. It is a great product.

This product uses a combination of humidity, ionization, ozone (O3) and air pressure to destroy bacteria and remove stains. All you do is hang up your shirts, turn it on and within minutes, the waterless system provides you with a clean, ironed shirt. It may seem large and cumbersome but youre getting a clean shirt every day. Plus its free of chemicals meaning the Earth is happy and your clothes last much longe:
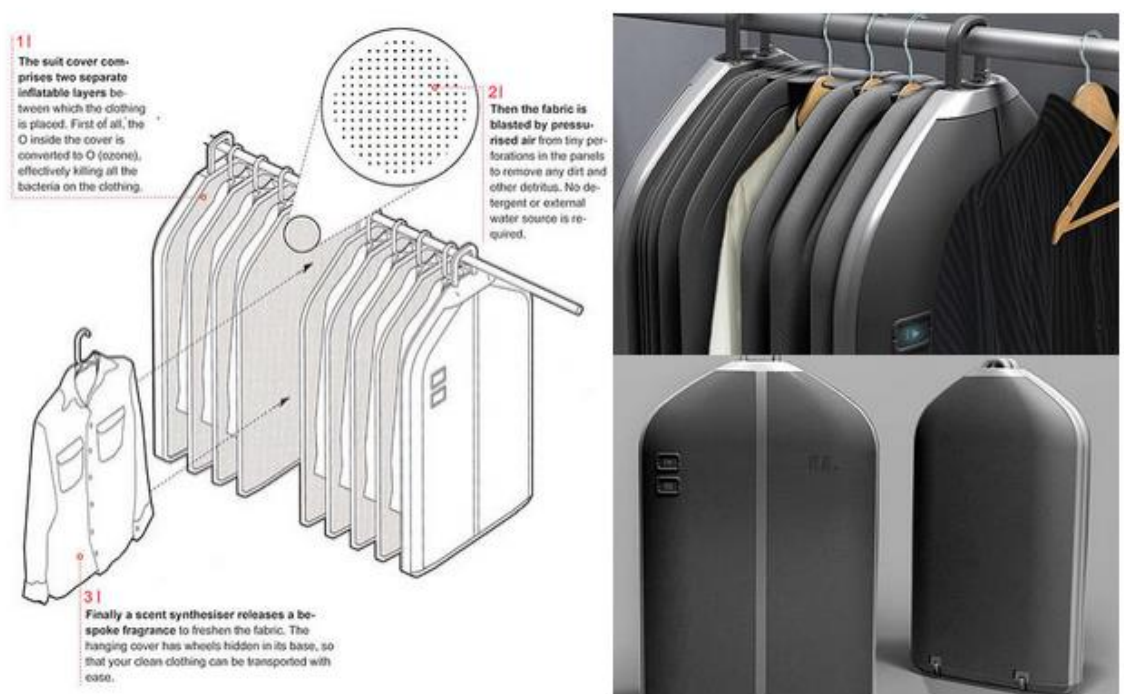

Human-like avatar for product 1 


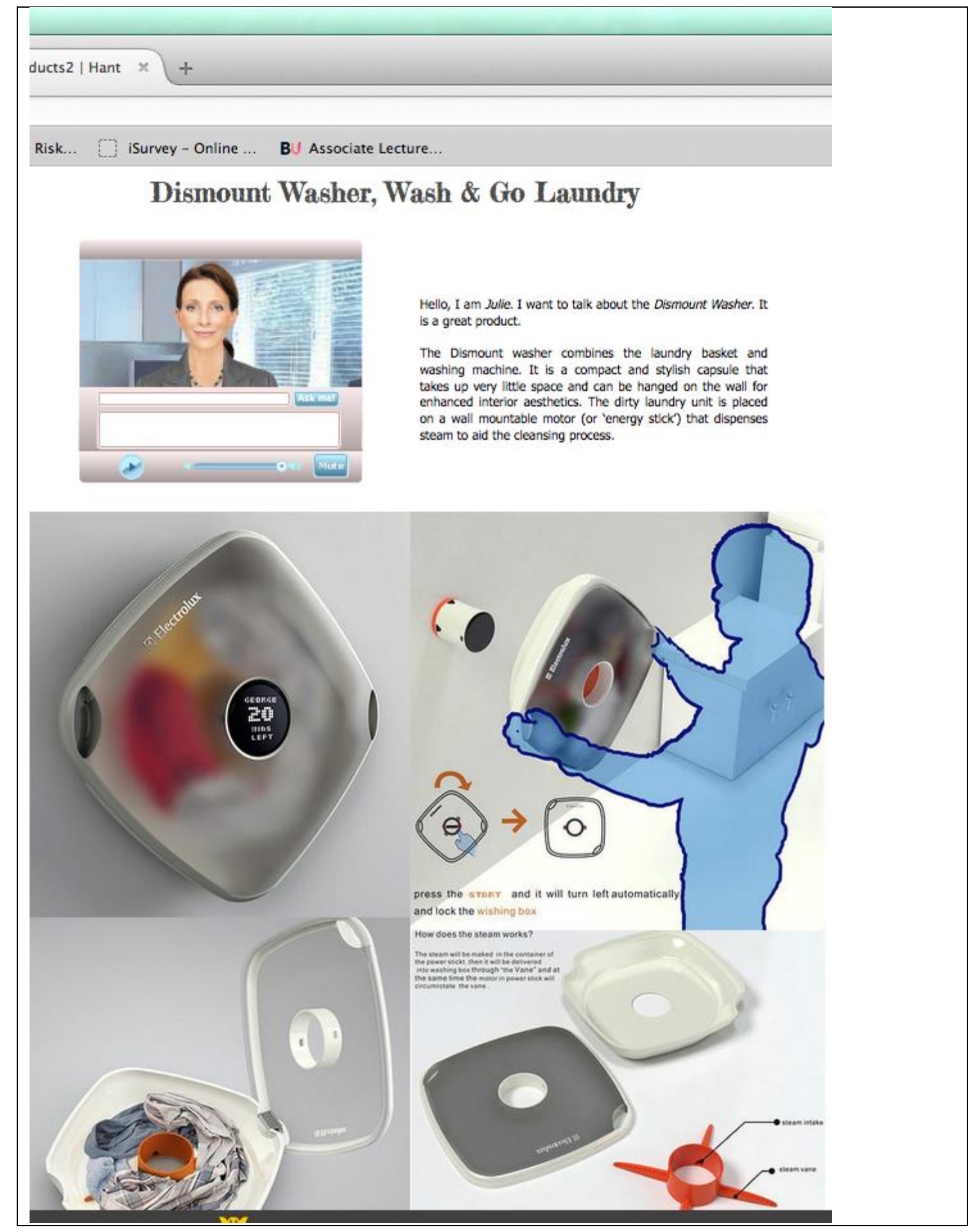




\section{Appendix B}

Measurement Scales

Comprehension Scale

Please complete the following statement

"I found the product description:

1- Difficult to understand/easy to understand

2- Confusing/straightforward" (from Phillips, 2000 p20)

"Please indicate the extent to which you agree with the following statements $(1=$ totally disagree, $7=$ totally agree):

1- After reading/listening to the product description, I have a very strong understanding of how this product works.

2- After reading/listening to the product description I would be able to use the product.

3- After reading/listening to the product description, I understand what the main features of this product are.

4- After reading/listening to the product description, I understand what the main benefits of this product are."

* "the product description" is a replacement for the phrase "the advert" and "reading/listening to" is a replacement for the phrase "reading" in the original scale (from Hoeffler, 2003)

$\underline{\text { Attitude Scale }}$

I evaluate the usage of the product as:

\begin{tabular}{|c|c|c|}
\hline \multicolumn{3}{|c|}{ HED/UT Scale } \\
\hline & 1 ---------------------------- 7 & \\
\hline Not Fun & & Fun \\
\hline Exciting & & Dull \\
\hline Not Delightful & & Delightful \\
\hline Thrilling & & Not thrilling \\
\hline Unenjoyable & & Enjoyable \\
\hline Effective & 1 -------------------------- 7 & Ineffective \\
\hline Unhelpful & & Helpful \\
\hline Functional & & Not functional \\
\hline Unnecessary & & Necessary \\
\hline Practical & & Impractical \\
\hline
\end{tabular}

$\underline{\text { Intention Scale }}$

Please select the appropriate rating for each statement ( $1=$ totally disagree, $4=$ Neutral, $7=$ totally agree $)$

(1) I will purchase the RNP

(2) Given a choice, my friends will choose the RNP

(3) There is a strong likelihood that I will buy the RNP 
(4) I would like to recommend the RNP to my friends.

Anthropomorphism scale

Please choose a rating between 1-10 for each item.

I perceive the website to be:

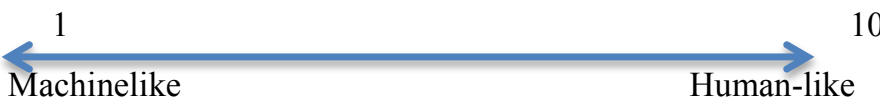
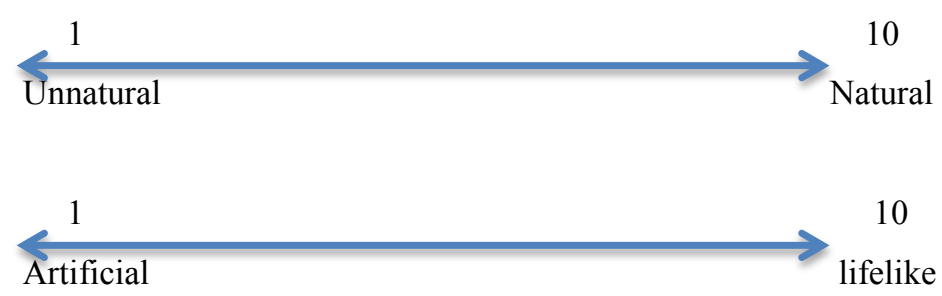

How well each adjective describes the website $(1=$ very poorly and $10=$ very well $)$

1- Likeable

2- Sociable

3- Friendly

4- Personal 


\section{Appendix C}

\section{Defining individual constructs}

The model is designed according to Hair et al (2010) steps. Step 1 is to define individual constructs. Table below indicates the constructs and the observed indicators.

\begin{tabular}{|c|c|c|c|}
\hline Construct & Scale Type & Description & Item \\
\hline \multirow[t]{3}{*}{$\begin{array}{l}\text { Mindful } \\
\text { Anthropomorp } \\
\text { hism (AntMF) }\end{array}$} & \multirow[t]{3}{*}{$\begin{array}{l}10 \text { points semantic } \\
\text { differential }\end{array}$} & $\begin{array}{l}\text { Please choose a number rating between 1- } \\
10 \text { to indicate how you perceived the } \\
\text { website. } \\
\text { Machinelike ---- Human-like }\end{array}$ & Ant MF1 \\
\hline & & $\begin{array}{l}\text { Please choose a number rating between 1- } \\
10 \text { to indicate how you perceived the } \\
\text { website. } \\
\text { Unnatural --- Natural }\end{array}$ & AntMF2 \\
\hline & & $\begin{array}{l}\text { Please choose a number rating between 1- } \\
10 \text { to indicate how you perceived the } \\
\text { website. } \\
\text { Artificial ---- Lifelike }\end{array}$ & AntMF3 \\
\hline \multirow[t]{4}{*}{$\begin{array}{l}\text { Mindless } \\
\text { Anthropomorp } \\
\text { hism (AntML) }\end{array}$} & $\begin{array}{l}1-10 \text { Likert } \\
\text { Very Poor - Very Well }\end{array}$ & $\begin{array}{l}\text { Looking at each of the adjectives below } \\
\text { indicate how well they describe the } \\
\text { website. } \\
\text { Likeable }\end{array}$ & AntML1 \\
\hline & $\begin{array}{l}1-10 \text { Likert } \\
\text { Very Poor - Very Well }\end{array}$ & Sociable & AntML2 \\
\hline & $\begin{array}{l}1-10 \text { Likert } \\
\text { Very Poor - Very Well }\end{array}$ & Friendly & AntML3 \\
\hline & $\begin{array}{l}1-10 \text { Likert } \\
\text { Very Poor - Very Well }\end{array}$ & Personal & AntML4 \\
\hline \multirow[t]{10}{*}{ Attitude (Att) } & \multirow[t]{10}{*}{$\begin{array}{l}10 \quad \text { points semantic } \\
\text { differential }\end{array}$} & $\begin{array}{l}\text { I evaluate the usage of the product as: } \\
\text { Not Fun ----- Fun }\end{array}$ & Att1 \\
\hline & & $\begin{array}{l}\text { I evaluate the usage of the product as: } \\
\text { Exciting ----- Dull }\end{array}$ & Att2R \\
\hline & & $\begin{array}{l}\text { I evaluate the usage of the product as: } \\
\text { Not Delightful -----Delightful }\end{array}$ & Att3 \\
\hline & & $\begin{array}{l}\text { I evaluate the usage of the product as: } \\
\text { Thrilling ----- Not Thrilling }\end{array}$ & Att4R \\
\hline & & $\begin{array}{l}\text { I evaluate the usage of the product as: } \\
\text { Unenjoyable ----- Enjoyable }\end{array}$ & Att5 \\
\hline & & $\begin{array}{l}\text { I evaluate the usage of the product as: } \\
\text { Effective ----- Ineffective }\end{array}$ & Att6R \\
\hline & & $\begin{array}{l}\text { I evaluate the usage of the product as: } \\
\text { Unhelpful ---- Helpful }\end{array}$ & Att7 \\
\hline & & $\begin{array}{l}\text { I evaluate the usage of the product as: } \\
\text { Functional ----- Not Functional }\end{array}$ & Att8R \\
\hline & & $\begin{array}{l}\text { I evaluate the usage of the product as: } \\
\text { Unnecessary ----- Necessary }\end{array}$ & Att9 \\
\hline & & $\begin{array}{l}\text { I evaluate the usage of the product as: } \\
\text { Practical ----- Impractical }\end{array}$ & Att10R \\
\hline \multirow[t]{2}{*}{$\begin{array}{l}\text { Comprehensio } \\
\mathrm{n}(\text { Comp) }\end{array}$} & $\begin{array}{l}10 \quad \text { points semantic } \\
\text { differential }\end{array}$ & $\begin{array}{l}\text { I found the product description: } \\
\text { Difficult to understand ----- Easy to } \\
\text { understand }\end{array}$ & $\begin{array}{l}\text { Compdes } \\
1\end{array}$ \\
\hline & $\begin{array}{l}10 \text { points } \\
\text { differential }\end{array}$ & $\begin{array}{l}\text { I found the product description: } \\
\text { Confusing ----- Straightforward }\end{array}$ & $\begin{array}{l}\text { Compdes } \\
2\end{array}$ \\
\hline
\end{tabular}




\begin{tabular}{|c|c|c|c|c|}
\hline & $\begin{array}{l}\text { 1-7 Likert } \\
\text { Strongly } \\
\text { Disagree }\end{array}$ & Agree-Strongly & $\begin{array}{l}\text { After reading/listening to the product } \\
\text { description, I have a very strong } \\
\text { understanding of how this product works }\end{array}$ & Comp3 \\
\hline & $\begin{array}{l}\text { 1-7 Likert } \\
\text { Strongly } \\
\text { Disagree }\end{array}$ & Agree-Strongly & $\begin{array}{l}\text { After reading/listening to the product } \\
\text { description I would be able to use this } \\
\text { product. }\end{array}$ & Comp4 \\
\hline & $\begin{array}{l}\text { 1-7 Likert } \\
\text { Strongly } \\
\text { Disagree }\end{array}$ & Agree-Strongly & $\begin{array}{l}\text { After reading/listening to the product } \\
\text { description, I understand what the main } \\
\text { features of this product are }\end{array}$ & Comp5 \\
\hline & $\begin{array}{l}\text { 1-7 Likert } \\
\text { Strongly } \\
\text { Disagree }\end{array}$ & Agree-Strongly & $\begin{array}{l}\text { After reading/listening to the product } \\
\text { description, I understand what the main } \\
\text { benefits of this product are }\end{array}$ & Comp6 \\
\hline $\begin{array}{l}\text { Purchase } \\
\text { Intention (PI) }\end{array}$ & $\begin{array}{l}\text { 1-7 Likert } \\
\text { Strongly } \\
\text { Disagree }\end{array}$ & Agree-Strongly & I will purchase the product & PI1 \\
\hline & $\begin{array}{l}\text { 1-7 Likert } \\
\text { Strongly } \\
\text { Disagree }\end{array}$ & Agree-Strongly & $\begin{array}{l}\text { Given a choice, my friends will choose the } \\
\text { product }\end{array}$ & PI2 \\
\hline & $\begin{array}{l}\text { 1-7 Likert } \\
\text { Strongly } \\
\text { Disagree }\end{array}$ & Agree-Strongly & $\begin{array}{l}\text { There is a strong likelihood that I will buy } \\
\text { the product }\end{array}$ & PI3 \\
\hline & $\begin{array}{l}\text { 1-7 Likert } \\
\text { Strongly } \\
\text { Disagree }\end{array}$ & Agree-Strongly & $\begin{array}{l}\text { I would like to recommend the product to } \\
\text { my friends }\end{array}$ & PI4 \\
\hline
\end{tabular}

Step 2 is to develop the overall measurement model. The initial and final measurement models are shown below. 
The initial CFA Model.

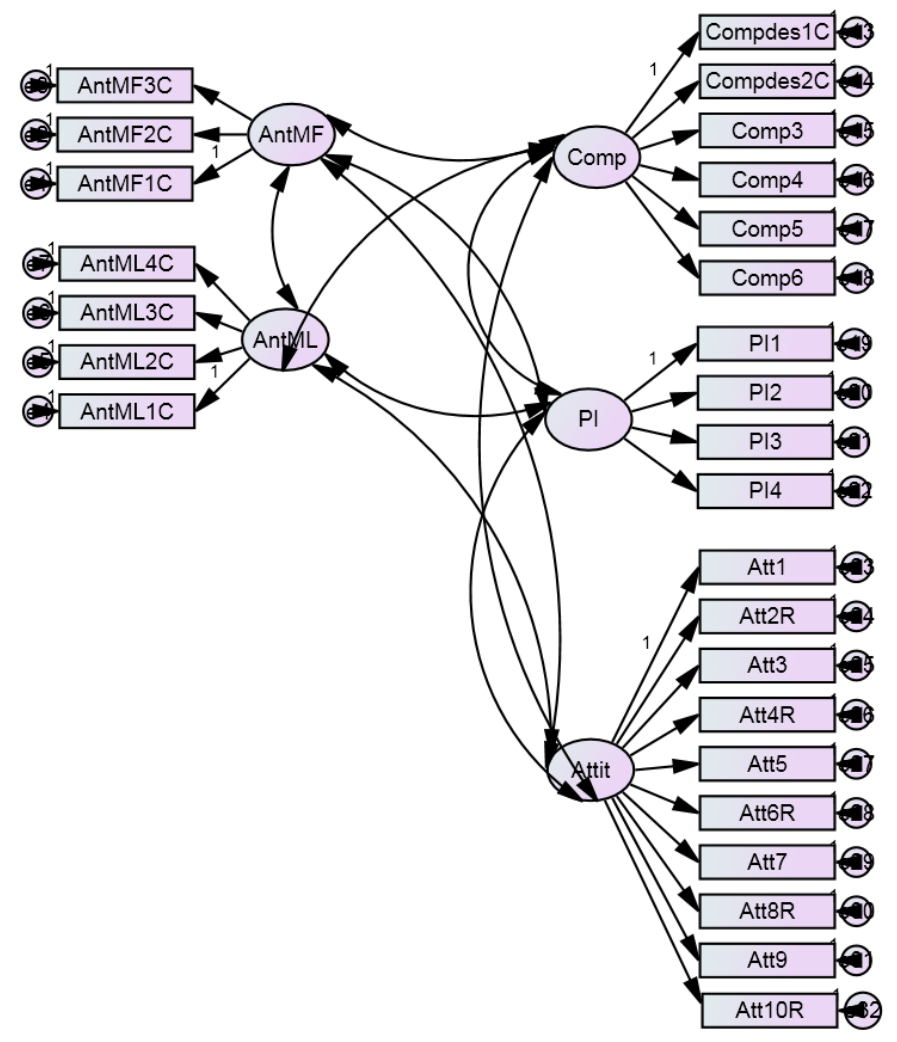


Final Model

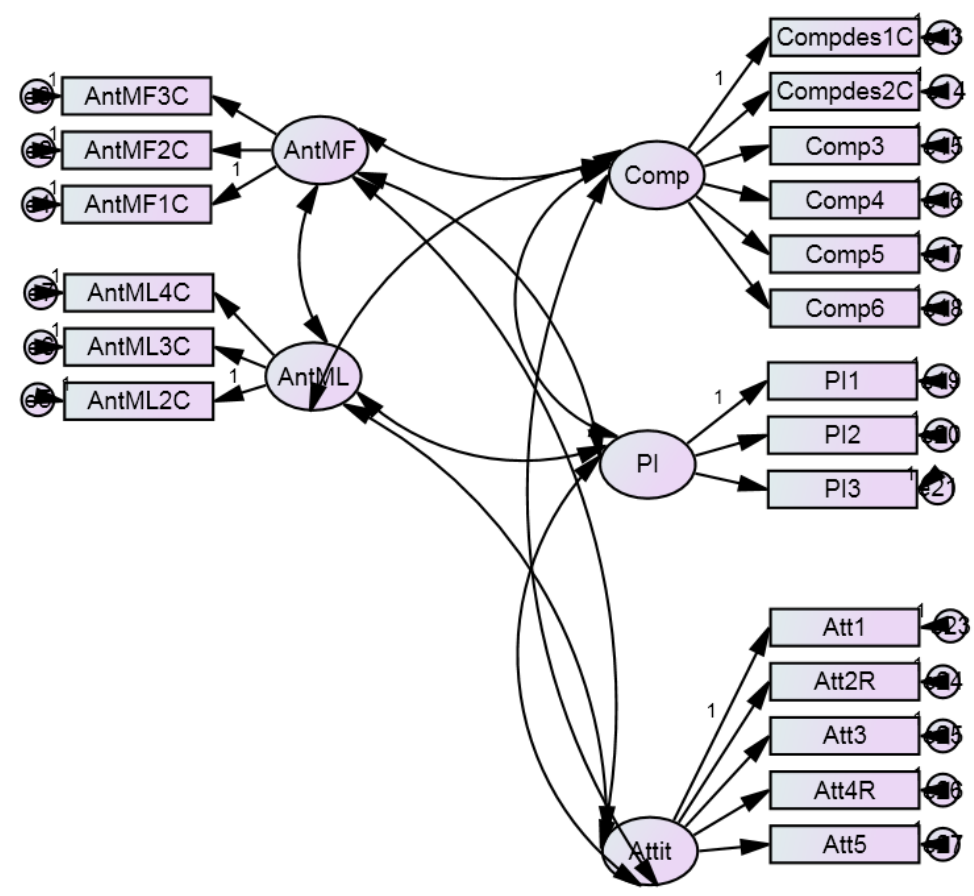




\section{Appendix D}

CFA Model Fit

Table D.1: CFA result for Mindful Anthropomorphism

\begin{tabular}{|l|l|l|}
\hline Scale item & & Factor Loading \\
\hline AntMF1C & & 0.799 \\
\hline AntMF2C & & 0.751 \\
\hline AntMF3C & 0.878 \\
\hline No item is removed during CFA. \\
KMO $=0.715 ;$ Bartlett's test $=653.869 ; \mathrm{df}: 3, \mathrm{p}=0.000$ \\
\hline
\end{tabular}

Table D.2: CFA result for Mindless Anthropomorphism

\begin{tabular}{|c|c|}
\hline Scale item & Factor Loading \\
\hline AntML2C & 0.918 \\
\hline AntML3C & 0.904 \\
\hline AntML4C & 0.831 \\
\hline
\end{tabular}

Table D.3: CFA result for Attitude

\begin{tabular}{|c|c|}
\hline Scale item & Factor Loading \\
\hline Att1 & 0.813 \\
\hline Att2R & 0.712 \\
\hline Att3 & 0.893 \\
\hline Att4R & 0.686 \\
\hline Att5 & 0.859 \\
\hline \multicolumn{2}{|c|}{$\begin{array}{l}\text { Five items removed during CFA } \\
\mathrm{KMO}=.849 ; \text { Bartlett's test }=1541.108 ; \mathrm{df}: 10, \mathrm{p}=0.000\end{array}$} \\
\hline
\end{tabular}

Table D.4: CFA result for Comprehension

\begin{tabular}{|c|c|}
\hline Scale item & Factor Loading \\
\hline Compdes1C & 0.789 \\
\hline Compdes $2 \mathrm{C}$ & 0.784 \\
\hline Comp3 & 0.875 \\
\hline Comp4 & 0.806 \\
\hline Comp5 & 0.825 \\
\hline Comp6 & 0.822 \\
\hline \multicolumn{2}{|c|}{$\begin{array}{l}\text { No item was removed during CFA } \\
\mathrm{KMO}=.856 ; \text { Bartlett's test }=2670.894 ; \mathrm{df}: 15, \mathrm{p}=0.000\end{array}$} \\
\hline
\end{tabular}

Table D.5: CFA result for Purchase Intention

\begin{tabular}{|c|c|}
\hline Scale item & Factor Loading \\
\hline PI1 & 0.953 \\
\hline PI2 & 0.830 \\
\hline PI3 & 0.961 \\
\hline \multicolumn{2}{|c|}{ One item removed during CFA. } \\
\hline
\end{tabular}




\section{Appendix E}

\section{Test of normality for each scale}

Figure E.1 displays the frequency distribution of the Mindful Anthropomorphism scale. The distribution appears to be close to normality. The result of the Kolmogorov-Smirnov (KS) test is significant ( $\mathrm{z}=0.086$, $\mathrm{p}=0.000)$ and Shapiro-Wilk (SW) is also significant $(\mathrm{w}=0.980, \mathrm{p}=0.000)$, which indicates that the observed distribution is non-normal. Shapiro-Wilk test appears to be the most powerful test for all types of distribution and sample sizes (especially for sample sizes larger than 30), in comparison with other tests such as Kolmogorov-Smirnov and Lilliefors (Razali and Wah, 2011); therefore according to SW, the variable is normal. However, for samples larger than 200, in order to make sure the sample is normal, rather than looking only at SW or KS tests, the kurtosis and skewness needs to be examined (Field, 2005, p.72) as KS test is extremely sensitive to minor departure from normality (Sharma, 1996) and also violating the assumption of normality is quite common in larger samples (Pallant, 2005, p.57). Moreover, it has been argued that skewness and kurtosis below the threshold of 1.96 will not cause significant issues in the dataset (Field, 2005, p.72 cited in Feiereisen 2009, p.226-227).

Looking at the skewness and kurtosis values, they are well below the threshold of $1.96(0.243,-0.700$ respectively); it is considered therefore that there is no serious concern regarding the normality of this variable, and it is preserved without transformation for future analysis.

Figure E.1. Histogram of mindful anthropomorphism

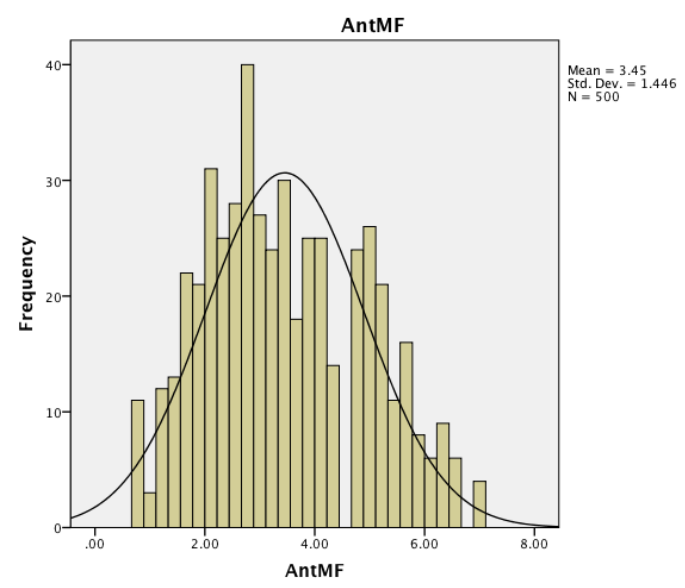

Figure E.2 displays the frequency distribution of the AntML scale. The distribution appears to be close to normality. Both KS $(\mathrm{KS})(\mathrm{z}=.058, \mathrm{p}=.000)$ and $\mathrm{SW}$ test $(\mathrm{w}=.984, \mathrm{p}=.000)$ are significant for AntML. The variable returns values of -0.216 and -0.465 for skewness and kurtosis respectively. These values are below the threshold of 1.96 therefore there is no serious concern regarding the normality of this scale and it will be retained for future analysis. 
Figure E.2. Histogram of Mindless Anthropomorphism

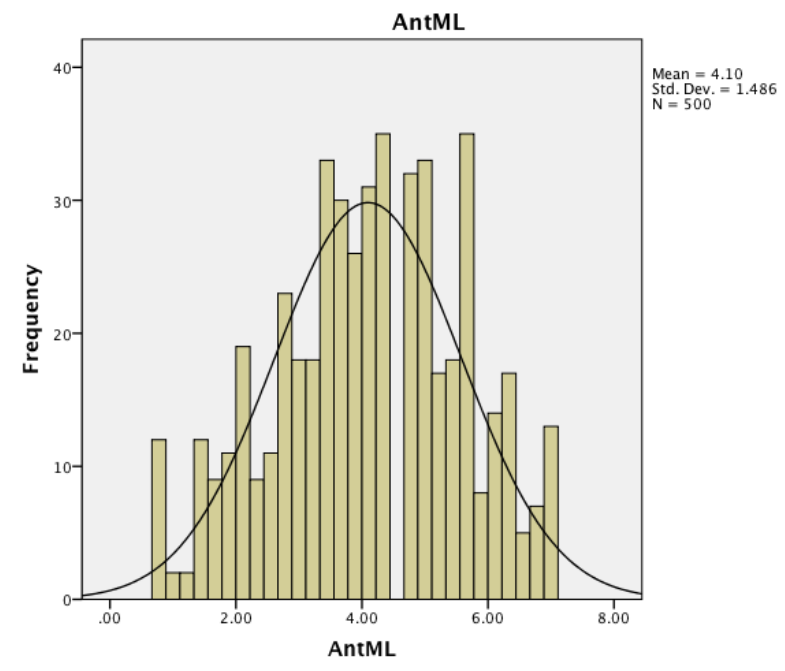

Figure E.3 displays the frequency distribution of the Comp scale. A skew towards higher values is evident. Both KS $(\mathrm{KS})(\mathrm{z}=.101, \mathrm{p}=.000)$ and SW test $(\mathrm{w}=.928, \mathrm{p}=.000)$ are significant for Comp. The variable returns values of -1.032 and 1.044 for skewness and kurtosis respectively. These values are below the threshold of 1.96 therefore there is no serious concern regarding the normality of this scale and it will be retained for future analysis.

Figure E.3. Histogram of Comprehension

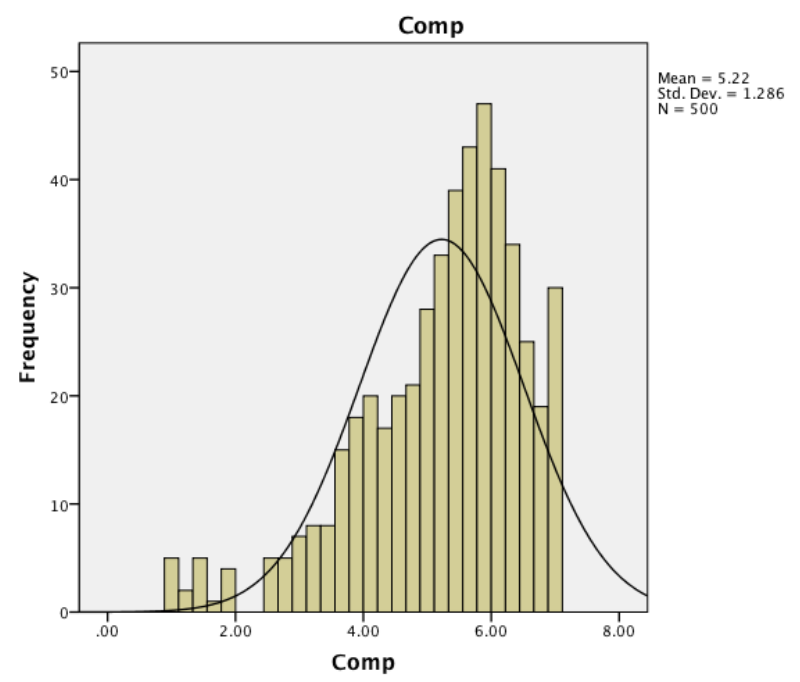

Figure E.4 displays the frequency distribution of the PI scale. The distribution appears to be normal. Both KS (KS) $(\mathrm{z}=.091, \mathrm{p}=.000)$ and SW test $(\mathrm{w}=.960, \mathrm{p}=.000)$ are significant for PT. The variable returns values of 0.031 and -1.028 for skewness and kurtosis respectively. These values are below the threshold of 1.96 therefore there is no serious concern regarding the normality of this scale and it will be retained for future analysis. 
Figure E.4. Histogram of Purchase Intention

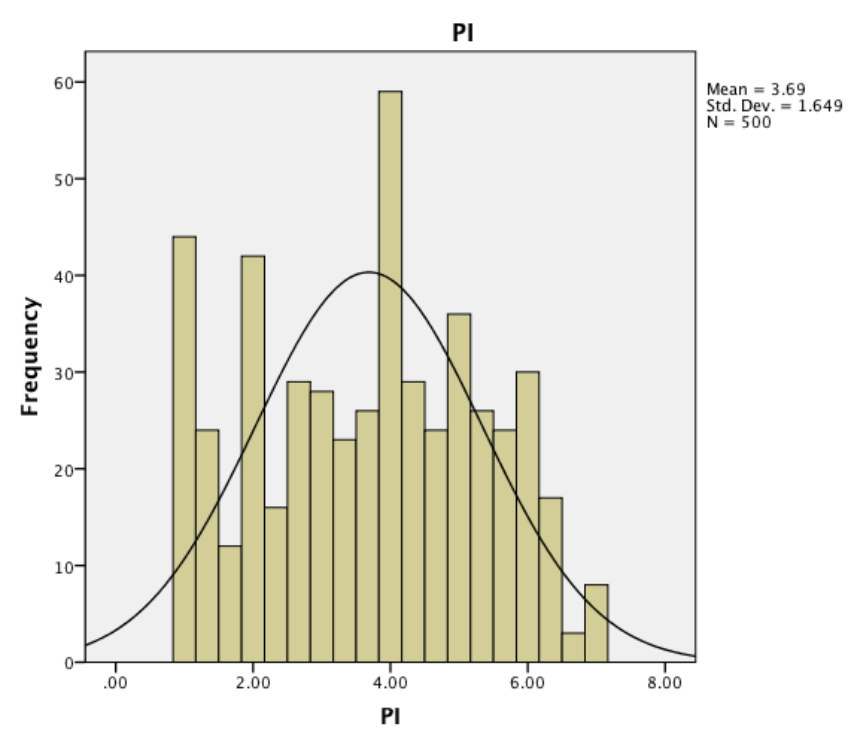

Figure E.5 displays the frequency distribution of the Attitude scale. The distribution appears to be normal. Both KS $(\mathrm{KS})(\mathrm{z}=.073, \mathrm{p}=.000)$ and $\mathrm{SW}$ test $(\mathrm{w}=.981, \mathrm{p}=.000)$ are significant for Attitude. The variable returns values of -0.356 and -0.089 for skewness and kurtosis respectively. These values are below the threshold of 1.96 therefore there is no serious concern regarding the normality of this scale and it will be retained for future analysis.

Figure E.5. Histogram of Attitude

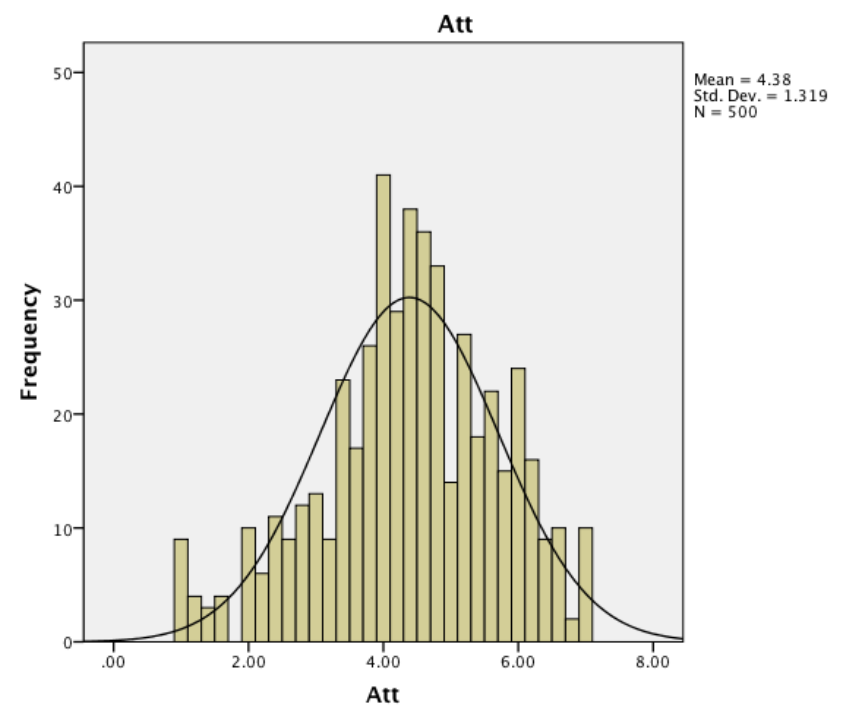

